ORNL/TM-2014/187

\title{
Overview of Modular HTGR Safety Characterization and Postulated Accident Behavior Licensing Strategy
}

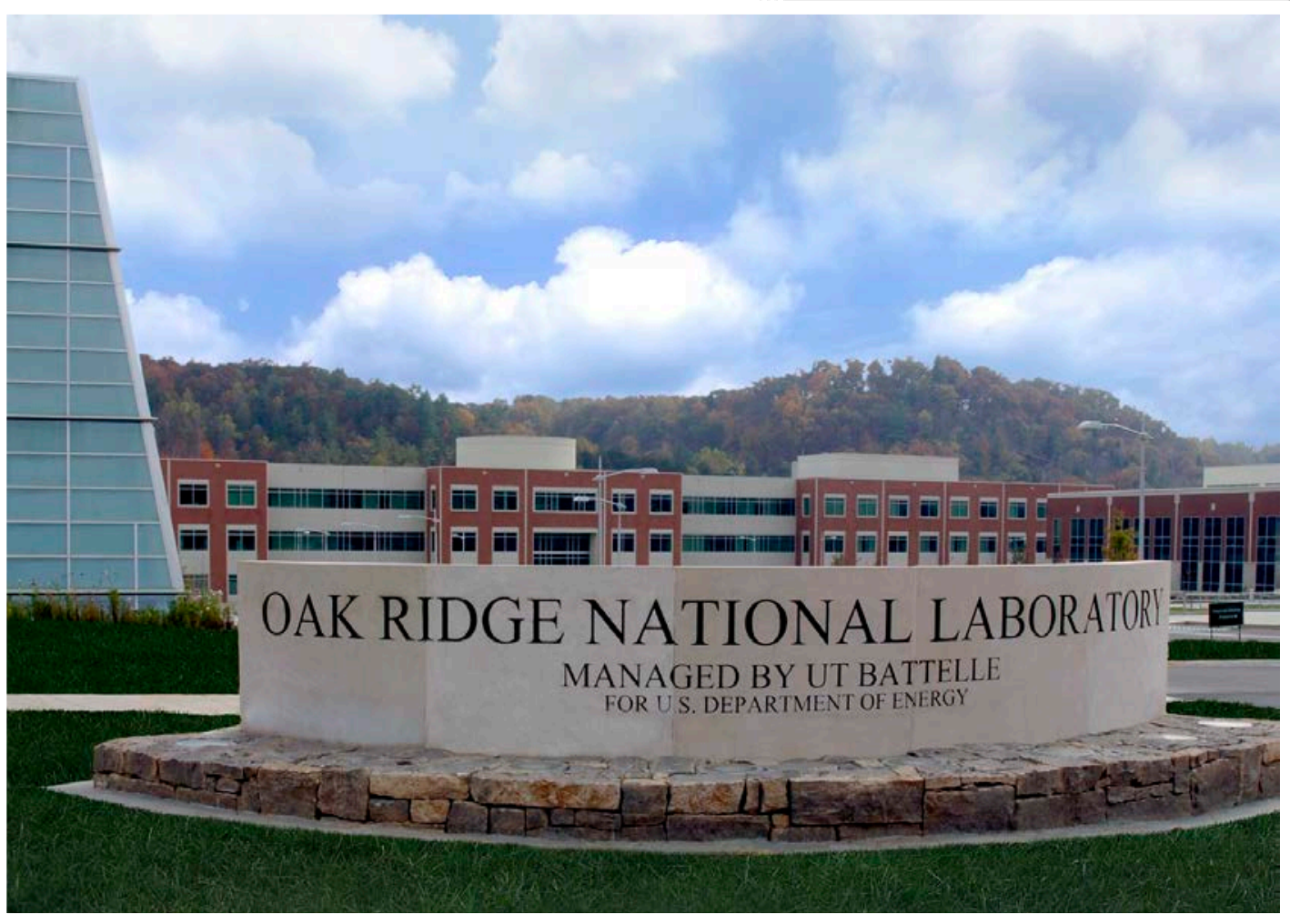

Aproved for public release; distribution is unlimited.

S. J. Ball

May 2014 


\section{DOCUMENT AVAILABILITY}

Reports produced after January 1, 1996, are generally available free via US Department of Energy (DOE) SciTech Connect.

Website http://www.osti.gov/scitech/

Reports produced before January 1, 1996, may be purchased by members of the public from the following source:

National Technical Information Service

5285 Port Royal Road

Springfield, VA 22161

Telephone 703-605-6000 (1-800-553-6847)

TDD 703-487-4639

Fax 703-605-6900

E-mail info@ntis.gov

Website http://www.ntis.gov/help/ordermethods.aspx

Reports are available to DOE employees, DOE contractors, Energy Technology Data Exchange representatives, and International Nuclear Information System representatives from the following source:

Office of Scientific and Technical Information

PO Box 62

Oak Ridge, TN 37831

Telephone 865-576-8401

Fax 865-576-5728

E-mail reports@osti.gov

Website http://www.osti.gov/contact.html

This report was prepared as an account of work sponsored by an agency of the United States Government. Neither the United States Government nor any agency thereof, nor any of their employees, makes any warranty, express or implied, or assumes any legal liability or responsibility for the accuracy, completeness, or usefulness of any information, apparatus, product, or process disclosed, or represents that its use would not infringe privately owned rights. Reference herein to any specific commercial product, process, or service by trade name, trademark, manufacturer, or otherwise, does not necessarily constitute or imply its endorsement, recommendation, or favoring by the United States Government or any agency thereof. The views and opinions of authors expressed herein do not necessarily state or reflect those of the United States Government or any agency thereof. 
Reactor and Nuclear Systems Division

\title{
OVERVIEW OF MODULAR HTGR SAFETY CHARACTERIZATION AND POSTULATED ACCIDENT BEHAVIOR LICENSING STRATEGY
}

\author{
S. J. Ball
}

Date Published: May 2014

Prepared by OAK RIDGE NATIONAL LABORATORY

Oak Ridge, Tennessee 37831-6283

managed by

UT-BATTELLE, LLC

for the

US DEPARTMENT OF ENERGY

under contract DE-AC05-00OR22725 



\section{CONTENTS}

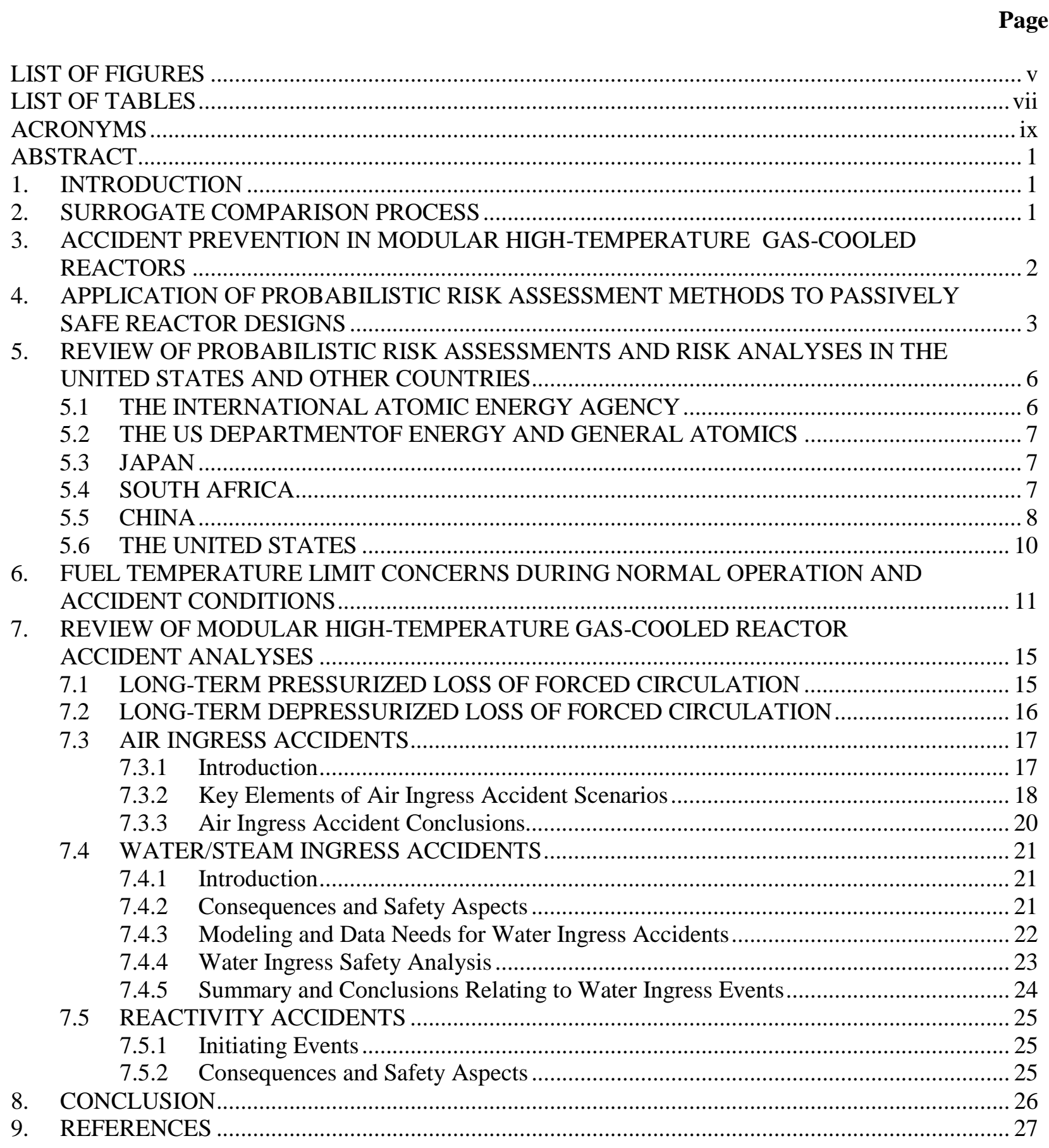





\section{LIST OF FIGURES}

Figure $\quad$ Page

Fig. 1. Example provision tree for control of reactivity at level 2 defense in depth................................. 4

Fig. 2. Example frequency vs consequence curve with defense-in-depths and success criteria................... 5

Fig. 3. Pebble Bed Modular Reactor PIRT status decision chart........................................................... 8

Fig. 4. TRISO fuel failure fraction vs time (h) at temperature. ........................................................... 12

Fig. 5. Fraction of calculated compact inventory released during the furnace test at $1600^{\circ} \mathrm{C} \ldots \ldots \ldots \ldots \ldots \ldots . . . . . .13$

Fig. 6. Core conduction cooldown test facility furnace heatup test data of advanced gas reactor fuel

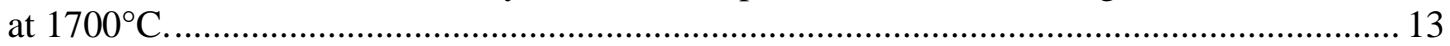

Fig. 7. Core conduction cooldown test facility furnace heatup test data of advanced gas reactor fuel at $1800^{\circ} \mathrm{C}$.

Fig. 8. Pebble friction factor (in helium) vs temperature $\left({ }^{\circ} \mathrm{C}\right)$.

Fig. 9. Predicted peak fuel temperatures vs time for P-LOFC, D-LOFC, and for D-LOFC accidents in which the RCCS fails (i.e., the "to ground" case, in which vessel heat is rejected to the below-ground silo). 



\section{LIST OF TABLES}

Table

Page

Table 1. Proposed top level regulatory criteria for a high-temperature reactor power module .................... 9

Table 2. Accident site boundary dose-limits comparison for various projects and countries..................... 10 



\section{ACRONYMS}

AGR

ATWS

BDBA

CCCTF

$\mathrm{CDF}$

CFP

DBA

DiD

D-LOFC

DOE

FP

GA

GRSAC

GSDC

GT-HTR-300

HTGR

HTR-PM

HTR-10

HTTR

IAEA

INET

INL

JAEA

JAERI

LERF

LOFC

LWR

MHTGR

NGNP

NRC

ORNL

PBMR

PIRT
Advanced Gas Reactor (DOE program)

anticipated transients without SCRAM

beyond-design-basis accident

Core Conduction Cool-Down Test Facility (ORNL)

core damage frequency

coated fuel particle

design-basis accident

defense-in-depth

depressurized loss-of-forced circulation

US Department of Energy

fission product

General Atomics

Graphite Reactor Severe Accident Code

general safety design criteria

Gas Turbine High-Temperature Reactor (Japan)

high-temperature gas-cooled reactor

High-Temperature Reactor-Power Module (China)

High-Temperature Reactor-10 MW (China)

High-Temperature Engineering Test Reactor (Japan)

International Atomic Energy Agency

Institute for Nuclear Engineering and Technology (China)

Idaho National Laboratory

Japan Atomic Energy Agency

Japan Atomic Energy Research Institute

large early release frequency

loss of forced circulation

light water reactor

Modular High-Temperature Gas-Cooled Reactor (DOE 1980s design)

next generation nuclear plant

US Nuclear Regulatory Commission

Oak Ridge National Laboratory

Pebble Bed Modular Reactor (South Africa)

phenomena identification and ranking table 


$\begin{array}{ll}\text { P-LOFC } & \text { pressurized loss of forced circulation } \\ \text { PRA } & \text { probabilistic risk assessment } \\ \text { PSID } & \text { preliminary safety information document } \\ \text { QHO } & \text { quantitative health objectives } \\ \text { R\&D } & \text { research and development } \\ \text { RCCS } & \text { reactor cavity cooling system } \\ \text { RCS } & \text { reactivity control system } \\ \text { RPV } & \text { reactor pressure vessel } \\ \text { SCRAM } & \text { emergency shutdown } \\ \text { SG } & \text { steam generator } \\ \text { TECDOC } & \text { IAEA technical document } \\ \text { TLRC } & \text { top-level regulatory criteria } \\ \text { TRISO } & \text { tristructural isotropic (particle fuel) }\end{array}$




\begin{abstract}
This report provides an update on modular high-temperature gas-cooled reactor (HTGR) accident analyses and risk assessments. One objective of this report is to improve the characterization of the safety case to better meet current regulatory practice, which is commonly geared to address features of today's light water reactors (LWRs). The approach makes use of surrogates for accident prevention and mitigation to make comparisons with LWRs. The safety-related design features of modular HTGRs are described, along with the means for rigorously characterizing accident selection and progression methodologies. Approaches commonly used in the United States and elsewhere are described, along with detailed descriptions and comments on design basis (and beyond) postulated accident sequences.
\end{abstract}

\title{
1. INTRODUCTION
}

This report includes a review of accident analyses and probabilistic risk assessments (PRAs) that have been used to-date for modular high-temperature gas-cooled reactors (HTGRs) and proposes a characterization of their safety features to make the features more readily adaptable to the US Nuclear Regulatory Commission's (NRC's) existing licensing practice. The intent is to minimize the impact on existing rulemaking by developing a set of generic, technology-neutral general design criteria. This is to be done by first identifying surrogate parameters that are comparable with those used by the NRC for current light water reactor (LWR) quantitative health objectives (QHOs), namely core damage frequency (CDF) and large early release frequency (LERF). An approach approved by the NRC is to first use surrogates in identifying the relative proportions of the safety design characterized by accident prevention and by accident mitigation. Accident prevention is more prominent in satisfying the safety goal set for advanced designs than it is for satisfying the goal set for current LWRs. The remaining task is to then use acceptable means to establish that the defense-in-depth (DiD) philosophy used in the design can be shown (via PRAs) to result in holding significant radioactivity release probabilities to an acceptable level. The NRC's 2013 safety goal (Secy-13-0029) is to limit the chance of a large release of radioactivity to $10^{-6}$ per reactor year.

\section{SURROGATE COMPARISON PROCESS}

The distinctions between "prevention" and "mitigation" should be clarified so that LWR and modular HTGR safety features can be characterized and compared in terms of their accident prevention and accident mitigation characteristics. Here, we assume that the design features that prevent accidents from occurring are the inherent ones, such that the reactor does not rely on external devices or actions to maintain it in a safe state. A strong negative temperature coefficient of reactivity would be one example. The mitigation features are those devices or actions that are relied on to prevent the reactor conditions from degrading to the next level during an initiating event or accident sequence. A well-designed, reliable SCRAM system is an example. The next section elaborates on the prevention features of the modular HTGR, and a case is made for the claim that prevention is the more prominent surrogate in meeting the safety goal than the HTGR mitigation features. 


\section{ACCIDENT PREVENTION IN MODULAR HIGH-TEMPERATURE GAS-COOLED REACTORS}

The case is made in the major design goal for the modular HTGR that accident prevention is the dominant (surrogate) factor in satisfying its safety goal:

No fuel failure for loss of coolant flow and coolant accidents, or for all foreseeable reactivity events, even with no corrective actions.

Implementation of this goal is achieved by utilizing the specific design and inherent safety features of the modular HTGRs, as defined by the International Atomic Energy Agency (IAEA) [Ref. 1]:

- $\quad$ high-quality ceramic coated-particle fuel;

- $\quad$ single-phase helium coolant with no heat-transfer limits;

- postshutdown decay heat removal achievable via a passive system (a reactor cavity cooling system [RCCS]); and

- a combination of ceramic core attributes, including

- low power density,

- large heat capacity,

- high thermal conductivity, and

— large margins between operating and "fuel damage" temperatures.

These core attributes lead to long response times for long-term loss of forced circulation (LOFC) accidents. Negative temperature-reactivity coefficients along with the large temperature margins accommodate all anticipated reactivity insertions with no resulting fuel damage. For the many (but necessary) conservatisms built into the design, there is always the question: "What does that buy you?" The resulting benefits are

- a simpler system (i.e., simpler design and operation),

- reduced reliance on engineered safety systems and operator actions,

- much more time to react to accident situations, and

- no need for a sealed (high-pressure) containment or public emergency planning.

Depending on the design details, there are caveats associated with the desired benefits:

- a SCRAM (or other reactivity relief) is needed within a day or two of an LOFC accident.

- there must be a reasonable limit on air ingress into the core in depressurization accidents.

- water ingress to core must be limited.

There is also the question of cost:

- a need to build in operating conservatisms to account for uncertainties,

- critical reliance on excellent fuel performance,

- licensing challenges to a filtered low-pressure containment design, and

- licensing challenges to reduced requirements for public emergency planning. 


\section{APPLICATION OF PROBABILISTIC RISK ASSESSMENT METHODS TO PASSIVELY SAFE REACTOR DESIGNS}

A characteristic of passive safety design reactors such as the modular HTGR is that there are no radioactivity releases beyond regulatory limits for any design-basis accidents (DBAs) or even for most (or all) postulated beyond-design-basis accidents (BDBAs). This implies that for accidents to be of licensing interest, initiating events must be very severe and, therefore, very unlikely (very low frequency). Hence, PRA consequences are calculated as a product of very rare events multiplied by the probability of failure of passive "defense" components and subsystems. On the other hand, more usual PRA consequences are determined by the product of more-likely events multiplied by the failure probability of active defense devices or subsystems. Much more input data exist for the latter case. Hence, for modular HTGRs, characterizing and determining frequencies for very rare initiators as well as quantifying the reliability of passive defense components or systems and the resulting consequences are problems and may call for a greater degree of certainty than usual in consequence determination analysis.

To establish valid PRA estimates for modular HTGR accidents of consequence, comprehensive studies need to be made for each of the major safety functions at each of the major levels of defense. Utilizing the IAEA guidelines described in IAEA-TECDOC-1366 [Ref.1], one can provide a path to obtaining useful consequence estimates. The three major safety functions are

- control of reactivity,

- control of core heat removal, and

- confinement of radioactive materials.

Occasionally a fourth safety function is included: control of chemical attack. Again, using IAEA methodology, the four applicable levels of DiD are

- prevention of deviations from normal operation and failures;

- control of abnormal operation and detection of failures;

- control of accidents within the design basis; and

- control of severe plant conditions, preventing accident progression, and mitigating consequences of BDBAs.

Insufficient control provisions at any given level can lead to progression of an accident to the next (higher) level.

For each event sequence, probabilities of accident progression and characterization of consequences can be evaluated via simulations (utilizing sensitivity studies) for each sequence path. As an example, the "objective provision tree” from Ref. 1 addresses the safety function "control of reactivity” at the Level 2 of its $\mathrm{DiD}$ (Fig. 1). Figure 1 shows cases where insufficient provisions are made in the various mechanisms (e.g., core overcooling, reactivity control system [RCS] malfunction) that would need to be corrected by other provisions, either in the reactor design or in its operation, to prevent the accident sequence from progressing to the next level (i. e., Level 3-DBA). The "insufficient provisions" note in Fig. 1 refers to cases where the combinations of inherent safety and mitigation features at the previous level (Level 1) are insufficient to prevent reactor conditions from degrading and reaching Level 2 (anticipated operational occurrences). 


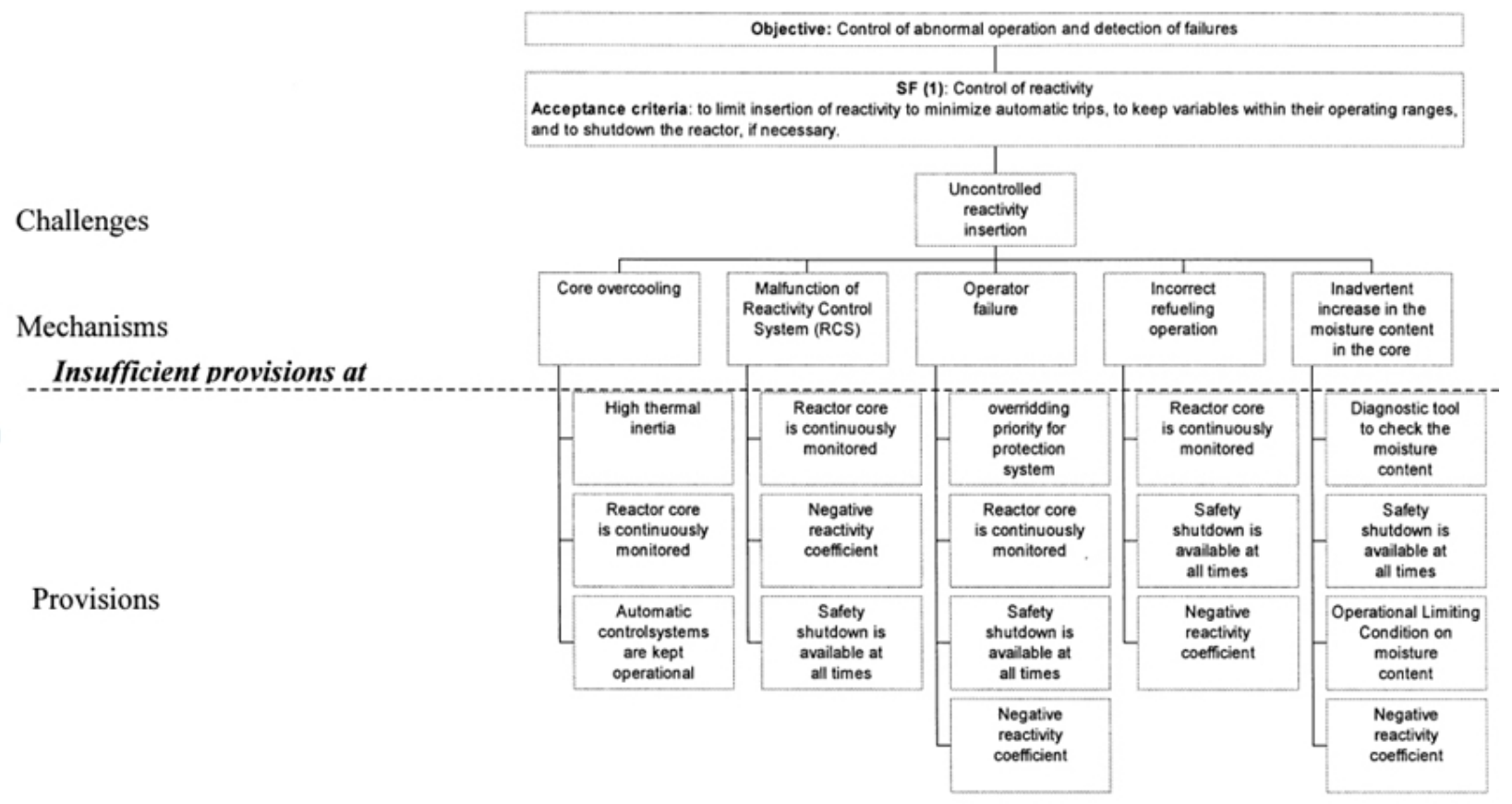

Fig. 1. Example provision tree for control of reactivity at level 2 defense in depth.(Source: International Atomic Energy Agency, Considerations in the Development of Safety Requirements for Innovative Reactors: Application to Modular High-Temperature Gas-Cooled Reactors, IAEA-TECDOC-1366, Vienna, Austria, August 2003.)

In this example, consider a core overcooling event (left column in Fig. 1). In an accident simulation, all feasible core-overcooling initiators would be considered so that it could be determined whether (for the expected range of negative reactivity coefficients) the core's high thermal inertia would prevent a damaging power level transient, with or without monitoring and operation of the RCS. Compiling simulations for this and other postulated event sequences (for the other safety functions and DiD levels) can eventually lead to a quantifiable QHO characterization, including potential plant damage, releases of radioactivity, and doses at the site boundary. Identification of specific provisions in the analysis (such as a core design with high thermal inertia or successful operation of the RCS) will enable assignment of the safety function to the appropriate surrogate category (i.e., one characterized by accident prevention, such as core thermal inertia, or by accident mitigation).

One of the main reasons that the CDF measure is not appropriate for modular HTGRs or for other small reactor concepts employing coated-particle fuel such as tristructural isotropic (TRISO) particles is that the major containment function for fission products is borne by the ceramic coatings, and there are billions of particles in a typical core. As long as defect fractions and failure rates are kept to an acceptable level, contamination of the primary system and the potential for other releases under accident conditions are minimal and well within limits. As a result, the measure used to quantify risk or safety characteristics is represented by a curve that shows consequences (i.e., dose to the public) vs frequency of an event or accident. A good example of such a curve, which also incorporates the DiD levels, is shown in Fig. 2. 


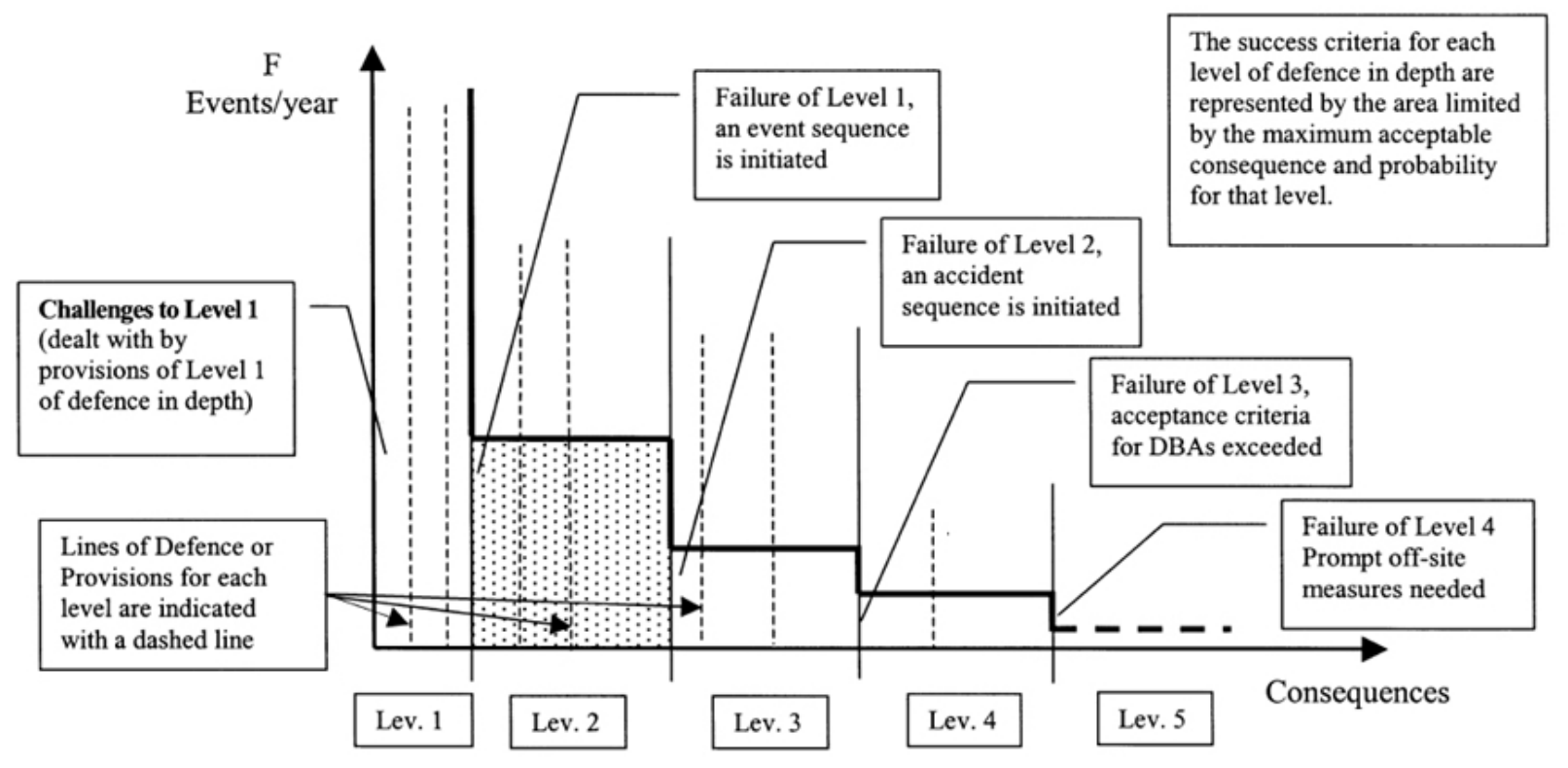

Fig. 2. Example frequency vs consequence curve with defense-in-depths and success criteria.

(Source: International Atomic Energy Agency, Considerations in the Development of Safety Requirements for Innovative Reactors: Application to Modular High-Temperature Gas-Cooled Reactors, IAEA-TECDOC-1366, Vienna, Austria, August 2003.)

This characterization helps to visualize the contribution of each level of defense to overall plant safety (log-log scales). Events that fall in the areas below the bold stair-step line are considered to present acceptable risk. A common quantitative substitute for "consequences" is dose (rem) at the exclusion area boundary.

The implementation of a DiD strategy for modular HTGRs also differs from that traditionally used for the current LWRs. The initial primary barriers (confining the radionuclides) are those in the TRISO fuel particles - the kernel and three protective coating layers, with the major barrier being a SiC layer. There are concerns about the effectiveness of the coated fuel particle in providing a containment function because billions of them are involved in the process. In the manufacturing process of the TRISO particles, the tolerances are tight for dimensional and structural characteristics of the fuel kernel and protective layers. Hence, there are concerns about the long-term effectiveness of the process control and quality assessment for batches of particles. However, the unique characteristics of TRISO fuel particles allow for considerations that further enhance their safety case [Ref. 1] due to "barrier diversity." The kernel and coating layers constitute successive barriers operating in parallel among the billions of particles that constitute a typical core. This population of parallel barriers cannot act in a uniform way in any conceivable circumstance because of the following variations:

- Variations within a batch-TRISO production with fluidized-bed coating processes results in statistical variations in kernel diameters, coating thicknesses, and structural characteristics within a given batch. Mean values and standard deviations in these properties are specified as a part of the fuel product acceptance criteria.

- Fabrication batches - the core at any given time will consist of hundreds of combinations of TRISO fuel element (compact or sphere) fabrication batches. 
- Service conditions - the core consists of a population of particles that undergo a broad range of service conditions, including spatial variations in temperature and neutron flux, as well as variations in time of service. Such variations produce a broad range of particle histories for the key performance parameters of temperature history, fluence, and burnup.

- Event conditions - when containment barriers are challenged in a given event (accident), particle conditions (mainly temperature) will vary over a very wide range, with the population mean temperature remaining far below the maximum fuel temperature.

This diversity allays concerns about the possibility that much of the core could consist of "weak" fuel (i.e., fuel that would perform well in normal operation and yet suddenly fail at lower-than-expected event temperatures). This characteristic has been referred to as "defense in breadth," working in conjunction with DiD.

\section{REVIEW OF PROBABILISTIC RISK ASSESSMENTS AND RISK ANALYSES IN THE UNITED STATES AND OTHER COUNTRIES}

A wealth of literature deals with risk studies of modular HTGR safety; the documents specifically note PRAs and accident analyses. An Oak Ridge National Laboratory (ORNL) multiyear task for NRC on supporting their "Knowledge Management" initiative resulted in compilation and categorization of hundreds of HTGR documents in risk studies and other safety-related areas in its Tomoye socialnetworking system [Ref. 2].

This section will summarize PRA and accident analyses approaches used by

- IAEA;

- the US Department of Energy (DOE) and General Atomics (GA), 1980s: the Modular HighTemperature Gas-Cooled Reactor (MHTGR);

- Japan via the Japan Atomic Energy Agency (JAEA), formerly the Japan Atomic Energy Research Institute (JAERI)*:

— the High-Temperature Engineering Test Reactor (HTTR) and

— the Gas Turbine High-Temperature Reactor (GT-HTR-300);

- South Africa: the Pebble Bed Modular Reactor (PBMR);

- China:

- the High-Temperature Reactor-10 MW (HTR-10) and

— the High-Temperature Reactor-Power Module (HTR-PM); and

- the United States: the Next Generation Nuclear Plant (NGNP)

Recent work on the NGNP is readily accessible and will also be summarized briefly in this section along with the noting of major current references.

\subsection{THE INTERNATIONAL ATOMIC ENERGY AGENCY}

The IAEA has had extensive coordinated research projects and programs dealing with HTGRs since the early 1990s, many of which dealt with safety and accident analysis issues. The most applicable from PRA and the NRC's risk-informed, performance-based regulatory framework is the IAEA technical document (TECDOC) dealing with development of safety requirements for advanced reactor concepts [Ref.1].

* On October 1, 2005, the Japan Atomic Energy Research Institute and the Japan Nuclear Cycle Development Institute were combined to form the Japan Atomic Energy Agency. 
Another applicable report is a later TECDOC for a technology-neutral safety approach [Ref. 3]. Other PRA-related activities are discussed in Sect. 4.

The IAEA contributions on accident analyses are noted in later sections. Because these analyses are characteristic of current code development efforts in essentially all the (HTGR-active) member states, the analysis work in the individual countries is covered by those descriptions.

\subsection{THE US DEPARTMENTOF ENERGY AND GENERAL ATOMICS}

The Preapplication Safety Evaluation Report (PSER) on the Modular High-Temperature Gas-Cooled Reactor (MHTGR) [Ref. 4] describes in detail the extensive review of the MHTGR design, which was carried out over a period of several years. It includes identification and analysis of key safety issues, event selection, and source term calculations. Specific issues concerning the low-pressure containment (confinement) and emergency planning are reviewed. Specific concerns are identified as to the uncertainties in calculations of shutdown reactivity margins, reactivity feedbacks with plutonium buildup, air ingress accident consequences, and water ingress effects.

\subsection{JAPAN}

JAEA, the Japanese agency primarily involved with modular HTGRs has an extensive research program centered on its operating experimental reactor (HTTR) and the design of GT-HTR-300, a larger power reactor (the "GT" refers to the gas turbine balance of plant). Extensive safety demonstration tests on the HTTR, including anticipated transients without SCRAM (ATWS) tests, were used to validate, to some extent, the passive safety characteristic of the reactor's basic design features.

The JAEA safety philosophy unique to modular HTGRs is captured succinctly in "Safety Logics for HTGR Safety Systems," a presentation by S. Shiozawa [Ref. 5]. The designs are such that "no severe core damage is expected for events with sequence frequencies more than $10^{-8}$ per reactor year, and that there is no need for public evacuation even in the worst event.” Its design of the GT-HTR-300 plant does not include a conventional high-pressure-resistant leak-tight vessel but does include a safety-grade RCCS. Reactivity (shutdown) systems include a main system with control (safety) rods and a backup injection of $\mathrm{B}_{4} \mathrm{C} / \mathrm{C}$ pellets. The confinement building (a reactor building with a limited leak rate) is designed to limit air ingress into the reactor core in the event of an air ingress accident (see Sect. 7.3). The reactor system is located in a concrete building with a compartmental structure.

The source term evaluation for the GT-HTR-300 includes estimates of primary system circulating activity and component radionuclide plate-out. The estimates are based on the assumption of an initial failure fraction limit for TRISO fuels of $5 \times 10^{-4}$. Fuel performance within this rate (fraction) was confirmed, in part, via experience with HTTR operation, although the fuel design for the large plant would be different.

For reactor conditions following a major depressurization accident, the source term calculation considered "realistic" (rather than conservative) estimations of fuel temperature increases, potential for fuel oxidation, fission product plate-out-liftoff scenarios, and confinement leakage and were able to meet Japanese QHO goals.

\subsection{SOUTH AFRICA}

South Africa's major project was the development of the PBMR, which began in 1997 and ended in 2008, due primarily to funding limitations. The PBMR philosophy from the start was to rely heavily on testing and demonstrations at the completed plant. The final stages of accident code validation would be to complete the verification and validation by relying on commissioning, operational data, and safety 
demonstration tests. The PBMR licensing process used phenomena identification and ranking table (PIRT) studies, where addition of an "action required" column made the evaluation process more useful. An example of a PBMR PIRT guideline chart is shown in Fig. 3 [Ref. 6].

\begin{tabular}{|c|c|c|c|c|c|c|}
\hline \multirow[t]{11}{*}{$\mathrm{P}$} & K & & & & \multirow{3}{*}{ Symptom } & \\
\hline & Status & Rank & \begin{tabular}{|c|} 
Confidence \\
in Rank \\
\end{tabular} & \begin{tabular}{|c|}
$\begin{array}{c}\text { Confidence } \\
\text { in Value }\end{array}$ \\
\end{tabular} & & \multirow{2}{*}{ A ction required } \\
\hline & Statas & (High / Lav) & \begin{tabular}{|l|} 
(Sure / \\
Unsure) \\
\end{tabular} & \begin{tabular}{|l|} 
(Sure / \\
Unsure) \\
\end{tabular} & & \\
\hline & 8 & High & Unsure & Unsure & $\begin{array}{l}\text { Phenomenon is perceived as } \\
\text { significant but is not well } \\
\text { known. }\end{array}$ & $\begin{array}{l}\text { High priority requirement for } \\
\text { analysis and validation. }\end{array}$ \\
\hline & 7 & High & Sure & Unsure & $\begin{array}{l}\text { P he nomenon is significant } \\
\text { and conide nce in value is low }\end{array}$ & $\begin{array}{l}\text { High priority requirement for } \\
\text { validation. }\end{array}$ \\
\hline & 6 & High & Unsure & Sure & $\begin{array}{l}\text { Phe nomenon is significant } \\
\text { and the confidence in rank is } \\
\text { low. }\end{array}$ & $\begin{array}{l}\text { High priority requirement for } \\
\text { analysis. }\end{array}$ \\
\hline & 5 & High & Sure & Sure & $\begin{array}{l}\text { P he nomenon is significant } \\
\text { and well known. }\end{array}$ & $\begin{array}{l}\text { Should be well represented in } \\
\text { the model. Should be readily } \\
\text { validated. }\end{array}$ \\
\hline & 4 & Low & Unsure & Unsure & $\begin{array}{l}\text { P he nomenon is not significant } \\
\text { but not well known. }\end{array}$ & $\begin{array}{l}\text { Requires analysis and } \\
\text { validation to determine rank } \\
\text { and value. }\end{array}$ \\
\hline & 3 & Low & Sure & Unsure & $\begin{array}{l}\text { P henomenon is not significant } \\
\text { and the confidence in value is } \\
\text { low. }\end{array}$ & $\begin{array}{l}\text { Lowpriority requirement for } \\
\text { validation. }\end{array}$ \\
\hline & 2 & Low & Unsure & Sure & $\begin{array}{l}\text { P he nomenon is not significant } \\
\text { and the confidence in rank is } \\
\text { low. }\end{array}$ & $\begin{array}{l}\text { Lowpriority requirement for } \\
\text { analysis. }\end{array}$ \\
\hline & 1 & Low & Sure & Sure & $\begin{array}{l}\text { Phe nomenon is well known } \\
\text { and is not significant. }\end{array}$ & $\begin{array}{l}\text { May be modelled without } \\
\text { validation. }\end{array}$ \\
\hline
\end{tabular}

Fig. 3. Pebble Bed Modular Reactor PIRT status decision chart. (Source: P. G. Robinson, "PBMR Safety Analysis Software Development and V\&V,” International Atomic Energy Agency Technical Meeting on Safety Aspects of MHTGRs, Beijing, China, October 2007.)

\subsection{CHINA}

The current program in China now centers on the design and construction of its HTR-PM. The Institute for Nuclear Energy Technology (INET), at Tsinghua University in Beijing, is responsible for the design and analysis, basing the design features and safety analysis on lessons learned (and validated, to some extent) from the design and operation of its 10-MW HTR-10 test reactor. As with Japan's HTTR, the HTR-10 underwent extensive safety demonstration tests, including ATWS tests from full power, to support China's safety validation cases.

INET's safety philosophy for their HTR-PM is described in detail by Y. Sun and D. Xue in “Considerations on General Safety Design Criteria of HTR-PM” [Ref. 7].

The current regulatory environment in China is based mostly on experience with water reactors, with regulatory standards leaning heavily on IAEA safety standards. To facilitate licensing for the HTR-PM, it was necessary to establish special general safety design criteria (GSDCs) The GSDCs are composed of the top-level regulatory criteria (TLRCs), key safety issues, and guides for the lower-level safety-related components and systems. The major issues addressed were the safety goal, safety analysis and acceptance 
criteria, the source term for siting and emergency planning, radioactivity confinement, and off-site emergency preparedness.

It was understood that, compared with existing LWRs, the HTR-PM needed to have more stringent safety requirements and a greater safety margin to allow proposed design features such as a vented reactor building and minimized off-site emergency preparedness (i.e., no emergency planning zone, no early public notice, and no public evacuation). The safety goals set for doses outside the plant boundary of the HTR-PM were a maximum of $5 \times 10^{-7}$ occurrences per plant year for acute fatality and $2 \times 10^{-6}$ per plant year for added risk of chronic cancer fatality. The goals were very similar to those set by the United States in 1986. Table 1 shows the proposed TLRCs set for the HTR-PM.

Table 1. Proposed top level regulatory criteria for a high-temperature reactor power module ${ }^{a}$

\begin{tabular}{lcc}
\hline \multicolumn{1}{c}{ Plant condition } & $\begin{array}{c}\text { Frequency range } \\
\text { (1/plant/year) }\end{array}$ & Dose limit $^{\text {b, }}$ \\
\hline Normal operation & $>1.0 \mathrm{E}-2$ & $0.25 \mathrm{mSv} / \mathrm{a}$ \\
Anticipated operational occurrence & $1.0 \mathrm{E}-2-1.0 \mathrm{E}-4$ & $0.25 \mathrm{mSv} / \mathrm{a}$ \\
Design-basis accident & & $5 \mathrm{mSv}$ (body) \\
& $1.0 \mathrm{E}-4-1.0 \mathrm{E}-6$ & $10 \mathrm{mSv}$ (thyroid) \\
Beyond-design-basis accident & $1.0 \mathrm{E}-6-1.0 \mathrm{E}-7$ & $100 \mathrm{mSv}$ (thyroid) \\
& & $50 \mathrm{mSv}$ (body) \\
\hline
\end{tabular}

${ }^{a}$ Source: Y. Sun and D. Xue, “Consideration on General Safety Design Criteria of HTR-PM,” International Atomic Energy Agency Technical Meeting on Safety Aspects of MHTGRs, Beijing, China, October 2007.

${ }^{b} 1 \mathrm{mSv}=100 \mathrm{mrem}$.

${ }^{c} / \mathrm{a}=$ per annum.

Comparisons with site boundary dose limits set by other projects (or countries) are shown in Table 2. 
Table 2. Accident site boundary dose-limits comparison for various projects and $\operatorname{countries}^{a, b, c}$

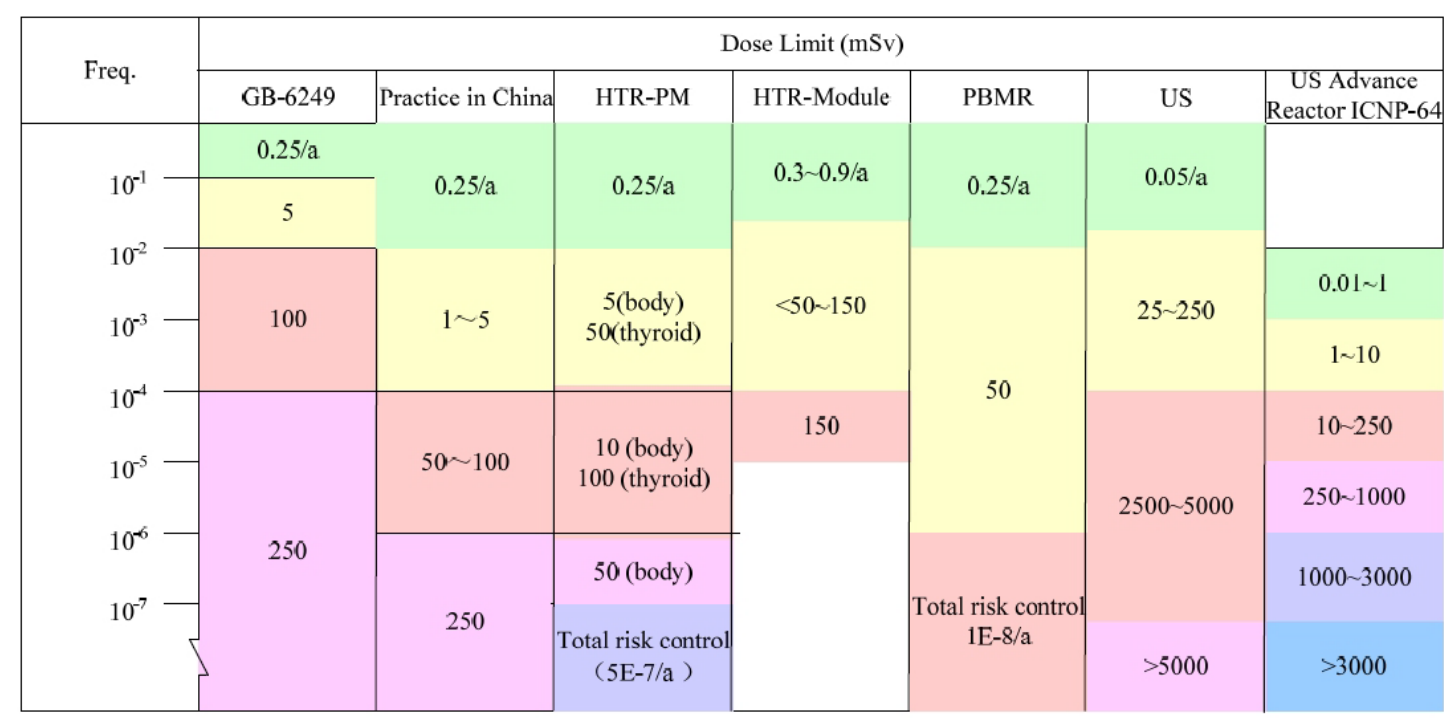

${ }^{a}$ Source: Y. Sun and D. Xue, “Consideration on General Safety Design Criteria of HTR-PM,” International Atomic Energy Agency Technical Meeting on Safety Aspects of MHTGRs, Beijing, China, October 2007.

${ }^{b} 1 \mathrm{mSv}=100 \mathrm{mrem}$.

$c / \mathrm{a}=$ per annum.

A mechanistic approach is used to define siting and emergency-planning source terms for the HTR-PM project; analyses of selected BDBAs, including both prompt and delayed releases, are used. The vented confinement structure is similar to that proposed by Japan; i.e., the early release in a rapiddepressurization accident is unfiltered, but later (low-pressure) releases are filtered. The HTR-PM licensing plan has been adopted, and construction of the first of 18 units resumed in December 2012. (Construction was delayed about one year to address reviews related to the Fukushima accident).

\subsection{THE UNITED STATES}

The recent effort in the United States centered on the NGNP. The extensive safety and licensing studies for the NGNP are summarized in an Idaho National Laboratory (INL) report, Modular HTGR Safety Basis and Approach [Ref. 8], and details can be found in the many references cited in that report. The report noted the primary safety objectives-i.e., limiting the doses from accidents such that regulatory requirements are met at a relatively nearby exclusion area boundary ( $\sim 00 \mathrm{~m}$ ) while eliminating the need for public evacuation or sheltering.

Following NRC recommendations, the United States uses risk-informed performance-based processes in its licensing approach for the NGNP demonstration plant. The risk-informed process is to ensure compliance with the TLRC, which includes providing for public health and safety via acceptable radiological-limiting consequences, independent of HTGR reactor type, and with well-defined risk criteria. This process involves application of the frequency vs consequence determinations (see Sect. 4 and Fig. 2).

The risk-informed methodology makes use of both probabilistic and deterministic components. PRA and DiD development incorporates insights and analyses from the MHTGR project as well as other 
international HTGR programs. The study also makes the case that the CDF and LERF metrics are not applicable to the NGNP. A follow-up report [Ref. 9] elaborates on the case.

The NGNP application of a DiD concept is somewhat different from the IAEA model noted earlier (see Sect. 5.1), in that it emphasizes the ideas of multiple barriers that prevent the releases of radioactive material to the environs. These barriers are the kernel and protective pyrolytic carbon and $\mathrm{SiC}$ coatings, the primary pressure boundary, and the filtering and holdup provided by the reactor. It also characterizes building-block elements of the DiD, which include the design capabilities (safety) features; programmatic aspects that involve processes such as operation, maintenance, testing, inspections, and accident prevention; and the accident risk management strategies.

An extensive (six-volume) NRC-sponsored NGNP PIRT study [Ref. 10], covers accident analysis and thermal fluids, fission-product transport, high-temperature materials, graphite, and process heat with cogeneration. A subsequent gap analysis report derived from the PIRT studies summarized and prioritized the areas where there are gaps between what is needed and what was available to NRC to adequately assess NGNP safety characteristics [Ref. 11]. A subsequent NGNP report describes research and development (R\&D) activities in six major areas, with schedules and budget estimates [Ref. 12]. R\&D gap areas covered in Ref. 12 are fuel and graphite development and qualification, high-temperature materials qualification, design and safety methods development and validation, heat transport and system integration, and hydrogen production.

\section{FUEL TEMPERATURE LIMIT CONCERNS DURING NORMAL OPERATION AND ACCIDENT CONDITIONS}

The typical modular HTGR core design is such that the maximum temperature of the fuel during a depressurized LOFC (D-LOFC) accident, absent any corrective actions as discussed in Sect. 3, would not exceed $1600^{\circ} \mathrm{C}$. Core designs also typically aim to keep peak fuel temperatures below $1000^{\circ} \mathrm{C}$ to $1100^{\circ} \mathrm{C}$ during normal full-power operation. There is a general concern about core coolant flow reductions in high-temperature areas in the core. Due to the increase in viscosity with temperature in helium and other gases, coolant path flow resistances increase with temperature, thus reducing the cooling where it is needed the most (a positive feedback process). This is known as "selective undercooling."

Studies of accident cases have shown that there would be no particle failures among typical TRISO particles, even for prolonged exposures at $1600^{\circ} \mathrm{C}$ (see Fig. 4) [Ref. 13]). Some fission product (FPs) could be released at high temperatures, even with no TRISO coating failures. For example, ${ }^{110 m} \mathrm{Ag}$ could escape and plate out on cooler primary system surfaces; however, it would not lift off in accident scenarios. 


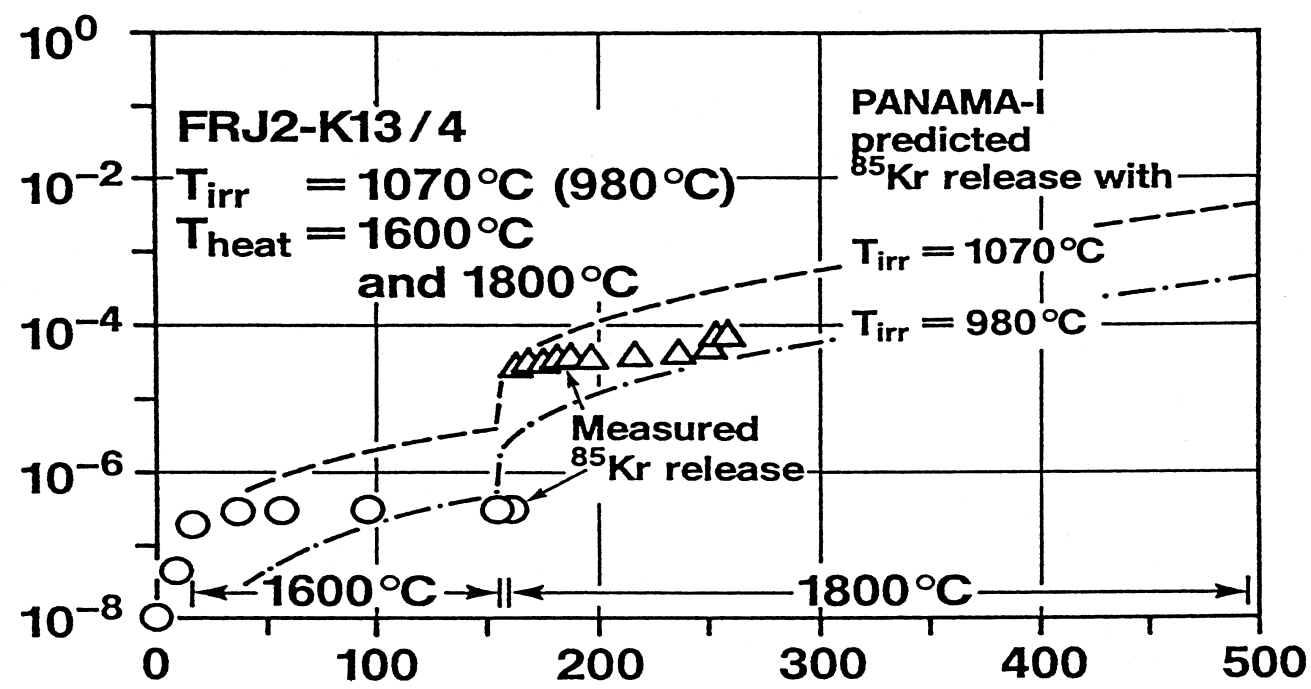

Fig. 4. TRISO fuel failure fraction vs time (h) at temperature. (Adapted from International Atomic Energy Agency, Fuel Performance and Fission Product Behavior in Gas-Cooled Reactors, IAEA-TECDOC-978, Vienna, Austria, November 1997.)

Similar conclusions from the US Advanced Gas Reactor (AGR) Program can be drawn from recent accident temperature simulation tests on irradiated TRISO fuel (average burnup of $~ 17 \%$ ) from the INL Advanced Test Reactor. Postirradiation examination of compacts underwent heatup testing at the ORNL Core Conduction Cool-Down Test Facility (CCCTF). Significant emphasis was given to evaluating the fuel performance at $1600^{\circ} \mathrm{C}$ to $1800^{\circ} \mathrm{C}$, temperature excursions above and well beyond those predicted in worst-case depressurized conduction cooldown events.

Figure 5 shows the measured releases of a prolonged fuel heatup test to $1600^{\circ} \mathrm{C}$ conducted at ORNL [Ref. 14]. Release of ${ }^{85} \mathrm{Kr}$ was monitored as an indicator of coating failure; no coating failure was detected. Subsequent analyses also showed that all SiC layers were still intact, although significant quantities of silver, europium, and strontium were recovered.

Silver release through intact $\mathrm{SiC}$ layers is expected, and the amount released was in line with that expected to already reside in the matrix of the irradiated compact. The very low cesium release shown does not necessarily indicate release through intact $\mathrm{SiC}$ during irradiation; some other sources could explain the small amount of cesium collected in the furnace (e.g., cesium contamination in the hot cells or trace uranium contamination outside the $\mathrm{SiC}$ in the as-fabricated fuel).

In contrast to the silver and cesium behavior, europium and strontium were detected on the CCCTF deposition cups throughout the 400-h test. Diffusion of europium and strontium through intact $\mathrm{SiC}$ cannot be ruled out, but it is more likely that the observed time-dependent collection on the deposition cups was mostly due to slow release of these elements from the carbon in the compact matrix into the CCCTF graphite holder.

Subsequent AGR testing at ORNL of the irradiated fuel at higher temperatures, $\left(1700^{\circ} \mathrm{C}\right.$ and $\left.1800^{\circ} \mathrm{C}\right)$, also showed excellent results (see Figs. 6 and 7 [Ref. 15]). 


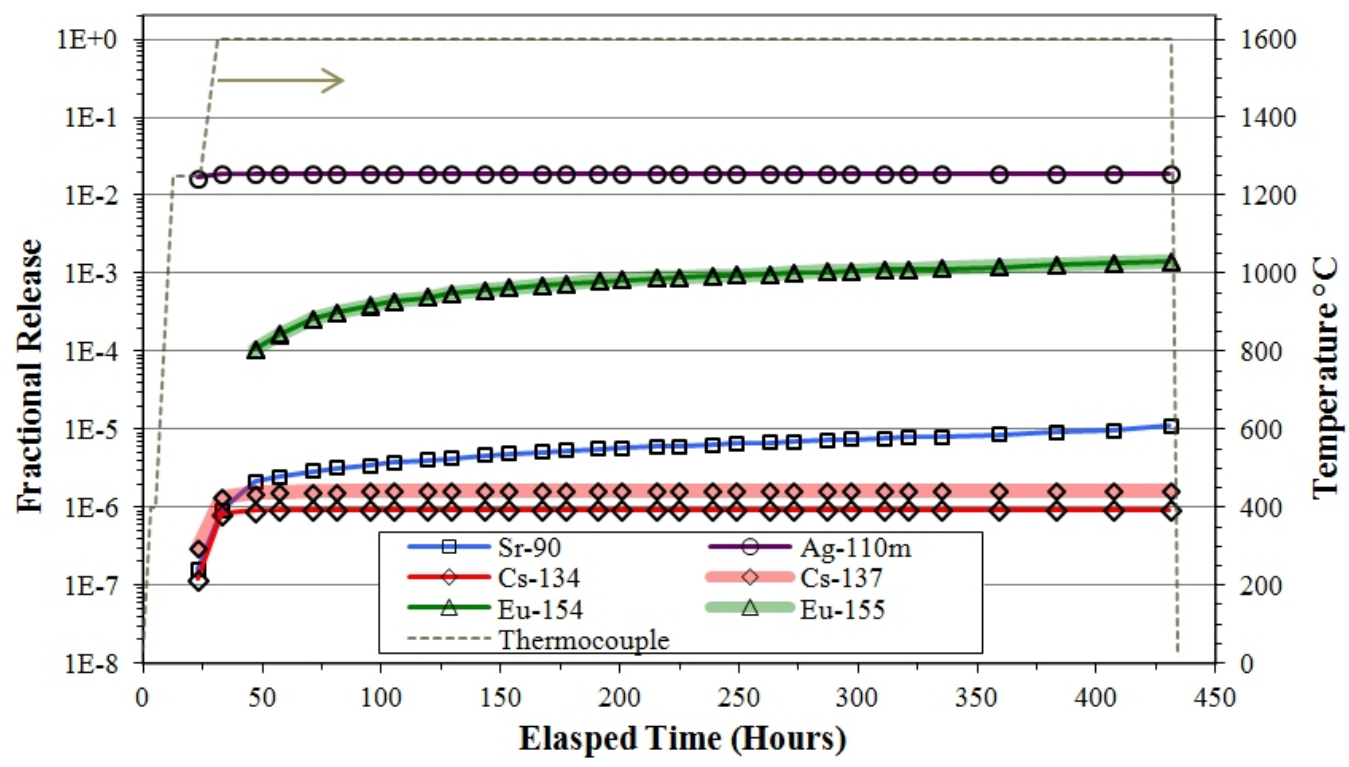

Fig. 5. Fraction of calculated compact inventory released during the furnace test at $1600^{\circ} \mathrm{C}$. Data points correspond to removal and analysis of deposition cups. (Source: C. A. Baldwin et al., "First Elevated-Temperature Performance Testing of Coated Particle Fuel Compacts from the AGR-1 Irradiation Experiment," Proceedings of the $6^{\text {th }}$ International Topical Meeting on High Temperature Reactor Technology HTR2012, Tokyo, Japan, October 28November 1, 2012.)

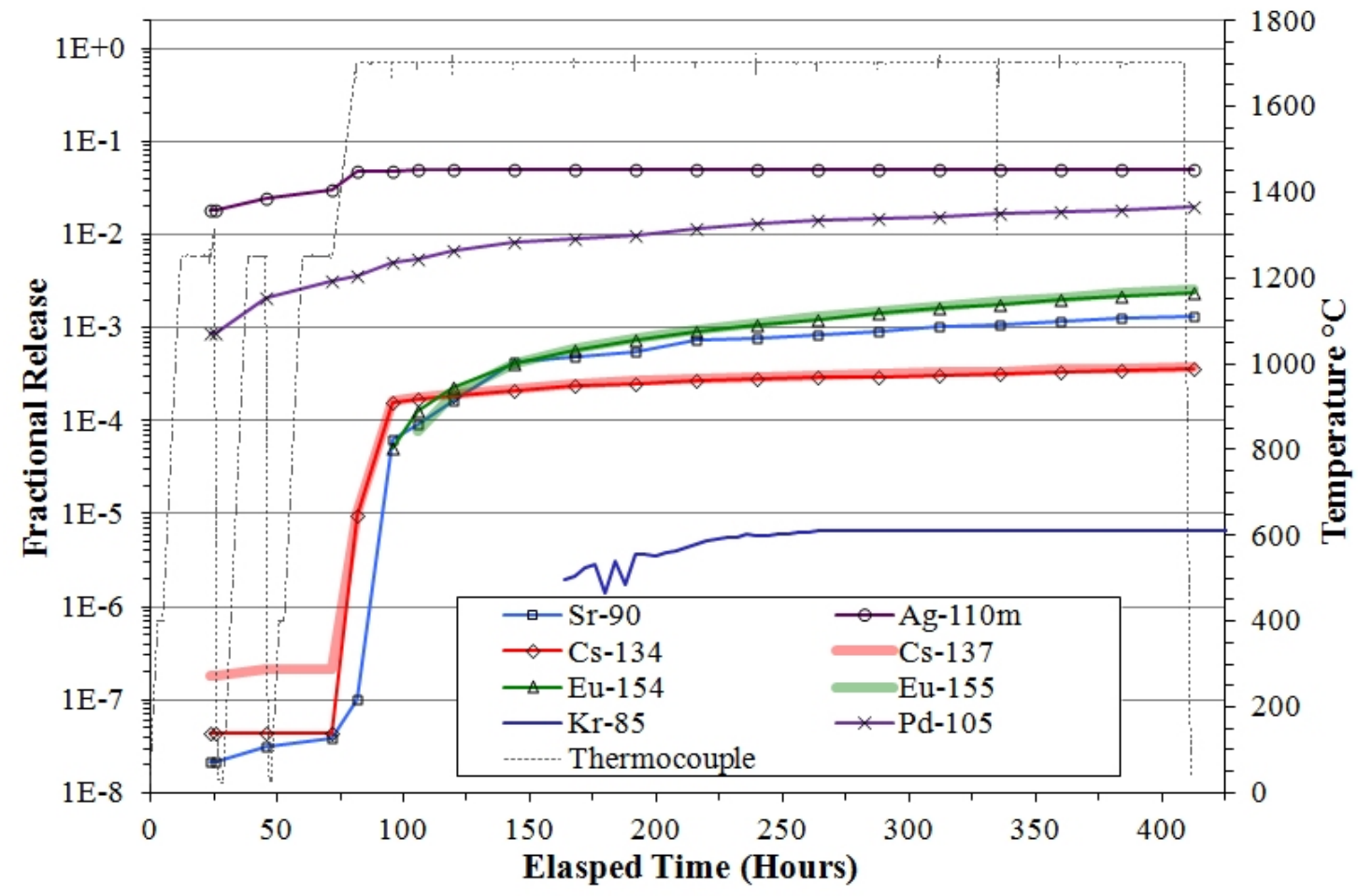

Fig. 6. Core Conduction Cool-Down Test Facility furnace heatup test data of advanced gas reactor fuel at $\mathbf{1 7 0 0}^{\circ}$ C. (Source: R. N. Morris et al., Performance of AGR-1 Fuel at Elevated Temperature: Fission Product Retention at 1600, 1700 , and $1800^{\circ} \mathrm{C}$, VHTR R\&D FY13 Technical Review Meeting, Idaho Falls, Idaho, May 7-9, 2013.) 


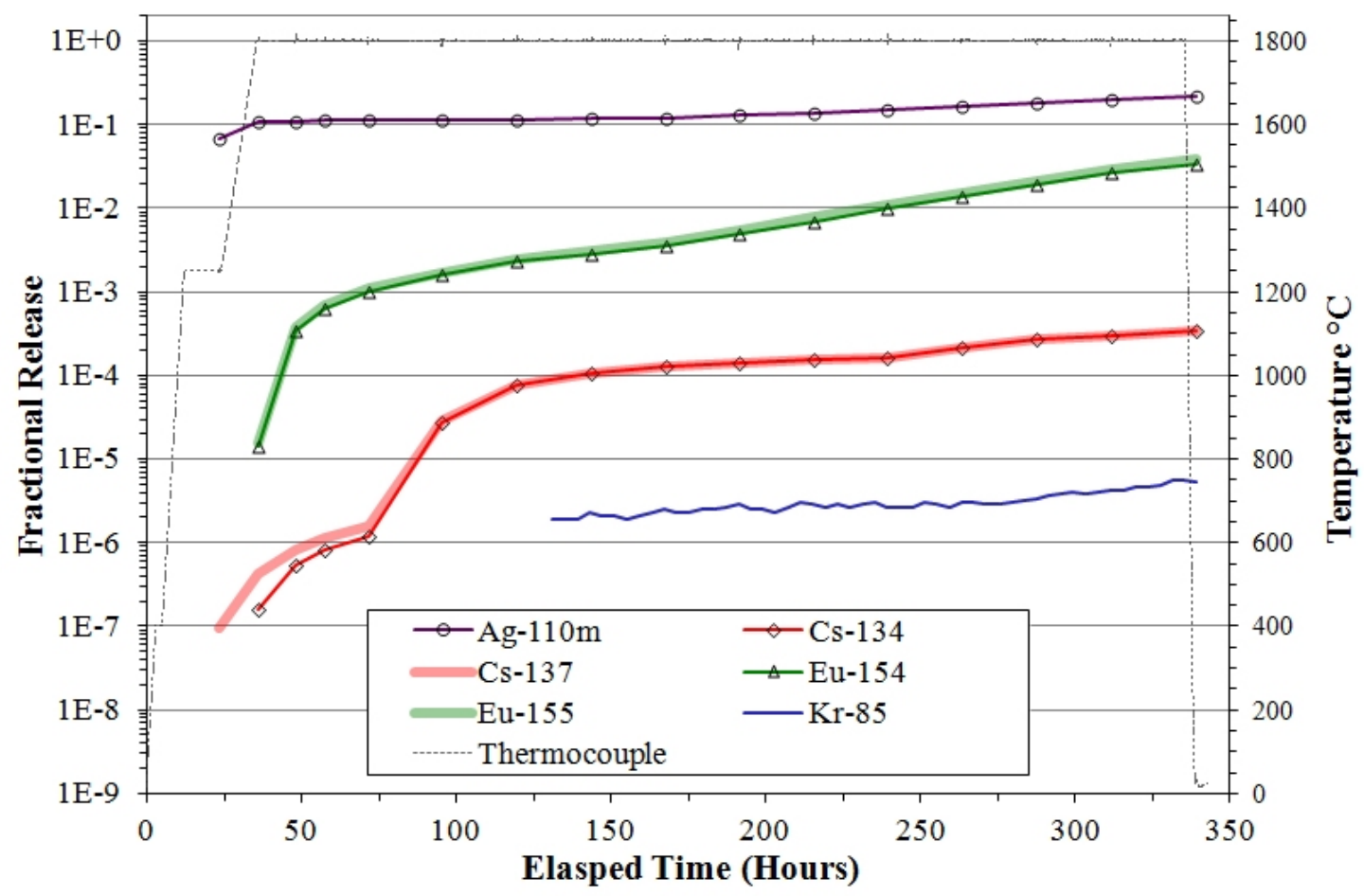

Fig. 7. Core Conduction Cool-Down Test Facility furnace heatup test data of advanced gas reactor fuel at $\mathbf{1 8 0 0}^{\circ}$ C. (Source: R. N. Morris et al., Performance of AGR-1 Fuel at Elevated Temperature: Fission Product Retention at 1600,1700 , and $1800^{\circ} \mathrm{C}$, VHTR R\&D FY13 Technical Review Meeting, Idaho Falls, Idaho, May 7-9, 2013.)

The releases collected during the accident testing in the temperature range of $1600^{\circ} \mathrm{C}$ and above imply that most of the elements come from the matrix rather than from diffusion through the coatings during the test. There is no reason to believe that rapid diffusion occurs at these accident temperatures.

Maximum fuel temperature concerns may arise due to uncertainties in the pebble bed fuel distribution (effective enrichment) that depend on the fuel loading schemes and on the paths that the pebbles take as they progress through the core. On-line refueling involves recirculating used pebbles several (about six to ten) times before they are diverted to a spent-fuel repository. A characteristic not typically considered in pebble distribution experiments and dynamic models is the decrease in pebble friction with temperature (Fig. 8) [Ref. 16]. The decrease tends to make the flow rate (and thus the power level) of the central core pebbles higher, which makes their temperature higher (another positive feedback process). This effect could also lead to higher-than-expected peak fuel temperatures in D-LOFC accidents. In addition, broken pebbles can block core exit paths for the intact pebbles. 


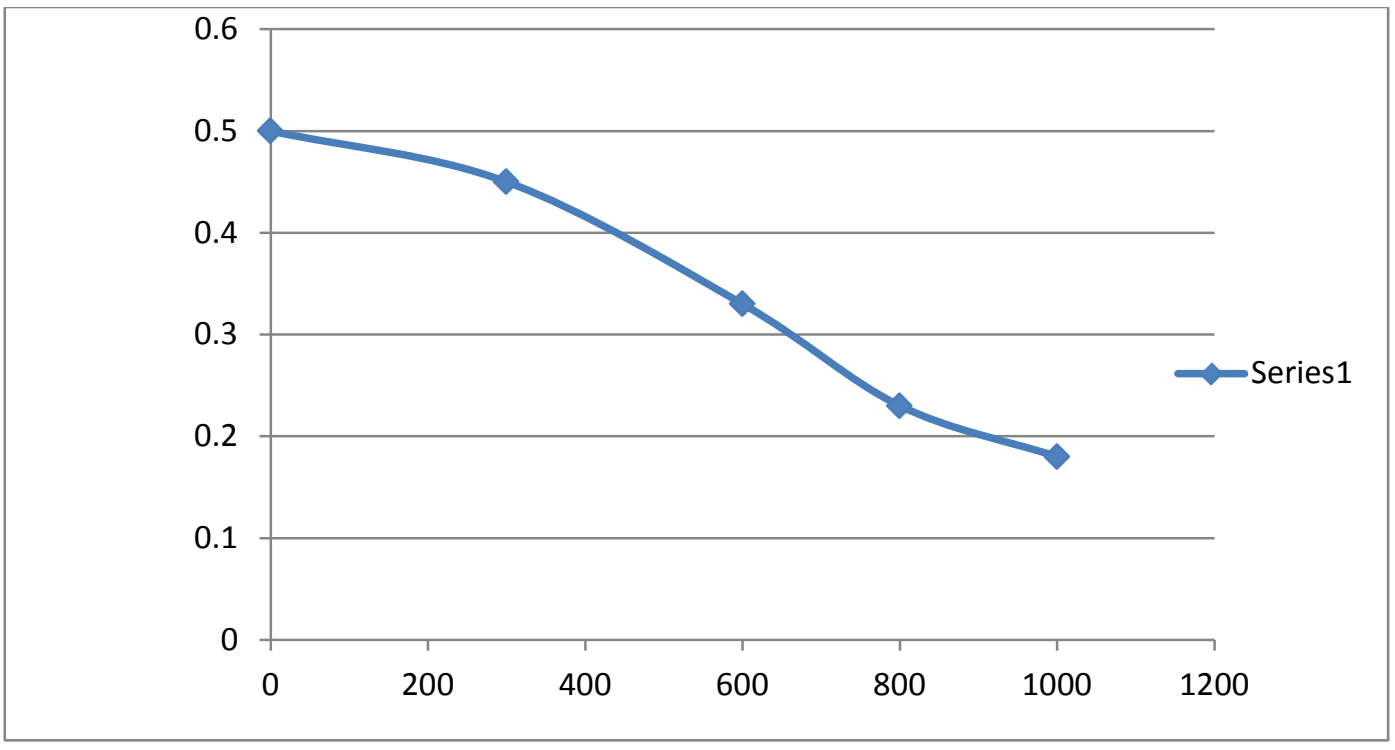

Fig. 8. Pebble friction factor (in helium) vs temperature $\left({ }^{\circ} \mathbf{C}\right)$. (Source: H. Kalinowski, "Core Physics and Pebble Flow-Examples from THTR Operation, Safety Aspects of HTR Technology”, NRC visit in Germany, 23-26 July 2001, GRS, pp. 430-447 and 11-13, Accession No. ML092250104 at http://adams.nrc.gov/wba/.)

\section{REVIEW OF MODULAR HIGH-TEMPERATURE GAS-COOLED REACTOR ACCIDENT ANALYSES}

Accident analyses for each of the countries and projects involved typically focus on the same set of postulated accident sequences:

- $\quad$ long-term pressurized LOFC (P-LOFC),

- D-LOFC,

- ATWS,

- long-term air ingress following D-LOFC,

- water/steam ingress,

- reactivity transients,

- loss of primary heat sink, and

- turbine trip/station blackout.

IAEA conducted a comprehensive survey of these accidents and reported in its safety reports series [Ref. 17]. Some specifics of the more interesting sequences are noted in the following sections.

\subsection{LONG-TERM PRESSURIZED LOSS OF FORCED CIRCULATION}

The typical reference-case P-LOFC for the modular HTGR assumes a flow coastdown and SCRAM at time $t=$ zero, the primary system remaining pressurized, and with the passive RCCS operational for the duration. Station blackout accident consequences are covered in predictions for P-LOFC accidents. Loss of electrical power typically results in a SCRAM.

The natural circulation of the pressurized helium coolant within the core tends to make core temperatures more uniform, therefore lowering the peak temperatures more than would be the case for a depressurized core, where the helium buoyancy forces would not establish significant recirculation flows. The chimney effect in P-LOFC events also tends to make the core (and vessel) temperatures higher near the top. 
Maximum vessel head temperatures are typically limited by judiciously placed insulation. Hightemperature alloys such as Alloy $800 \mathrm{H}$ may be used for the core barrel to allow for headroom in that area. For reference P-LOFC events, the peak fuel temperatures typically occur after about one day. In P-LOFCs, the peak fuel temperature is not a concern. The usual concern is more likely to be the maximum vessel temperature and the shift in peak heat load to near the top of the reactor cavity, resulting in the axial distribution of maximum fuel temperature peaking toward the inlet (or top) of the core. Depending on the high-temperature capabilities of the vessel steel, some special adaptations of vessel insulation strategies may be applied.

The parameter most likely to affect the success of P-LOFC outcomes, assuming that the RCCS is functioning properly, is the emissivity controlling the radiation heat transfer between the vessel and the RCCS (typically assumed to be $\sim 0.8$ over the full range of accident temperatures).

\subsection{LONG-TERM DEPRESSURIZED LOSS OF FORCED CIRCULATION}

The typical D-LOFC reference case assumes a rapid depressurization along with a primary circulation flow coastdown and SCRAM at time $t=$ zero, and with the passive RCCS operational. It also assumes that the depressurized coolant is helium (i.e., no air ingress). This event is also known as a "conduction heatup" (or "conduction cooldown") accident because the core effective conductivity is the dominant mechanism for the transfer of afterheat from the fuel to the vessel. In the reference case, the maximum fuel temperature peaks (by design) just below the target design temperature of $1600^{\circ} \mathrm{C}$. This peak typically occurs about two days into the transient, and the maximum vessel temperatures occur later. For the D-LOFCs, the peak fuel (and vessel) temperatures are near the core beltline, or midplane, rather than near the top as in the P-LOFC, because the convection effects for atmospheric-pressure helium are insignificant.

Several parameter variations are of interest for a D-LOFC accident, which is generally considered to be the defining accident for determining the "reference case accident peak fuel temperature.” These variations are effective core graphite conductivity (which is a significant function of irradiation history, temperature, orientation, and annealing effects); afterheat power vs time after shutdown; and power peaking factor distribution in the core after shutdown. If maximum vessel temperatures are of concern, emissivity effects should also be considered. The effective core conductivity for pebble bed core designs is more related to thermal radiation effects between pebbles than just the graphite material conductivity. Characterization of this effective bed conductivity is a critical factor in the design and is the subject of many experimental programs.

The topic of breaks in the primary system is very complex because the breaks can be postulated as happening anywhere in the system and range from a break in a small instrument line to a double-ended sudden rupture of the cross-duct vessel. Although such a break is generally considered to be well below the $10^{-8}$ events per reactor year criterion, NRC in the past has requested consideration of this event during its reviews of the MHTGR [Ref. 18].

One of the accident sequences of most concern involves the means for avoiding long-term air (oxygen) ingress following depressurization.

Reactor building filters are designed to open (i.e., not provide filtering) in the case of a rapid depressurization, based on the assumptions that there would be little primary system circulating activity and that very little of the plated-out FPs would lift off. 
For pebble-bed designs, there are concerns that radioactive dust in the primary could be resuspended and ejected to the environs, perhaps unfiltered, in rapid-depressurization LOFC accidents. This postulated accident is currently the subject of considerable interest in the HTR-PM project.

For very rapid D-LOFC cases, damage to components (both inside and outside the primary system) could occur from shock and vibrations and from being hit by very hot helium jets.

Failures of the safety-grade, passive RCCS along with LOFC accidents are considered beyond design basis. Even so, predicted peak fuel temperatures for D-LOFC accidents are typically in the $1600^{\circ} \mathrm{C}$ range (see Fig. 9). Figure 9 is from a GA presentation at the MHTGR Technology Course for NRC and DOE, September 10-14, 2001, Germantown, Maryland. GA's observation was verified by independent analyses by ORNL and Brookhaven National Laboratory (see Appendices A and B of Ref. 4). The main problem here would be excessively high reactor pressure vessel (RPV) temperatures after a day or two if no remedial RCCS corrective action were taken.

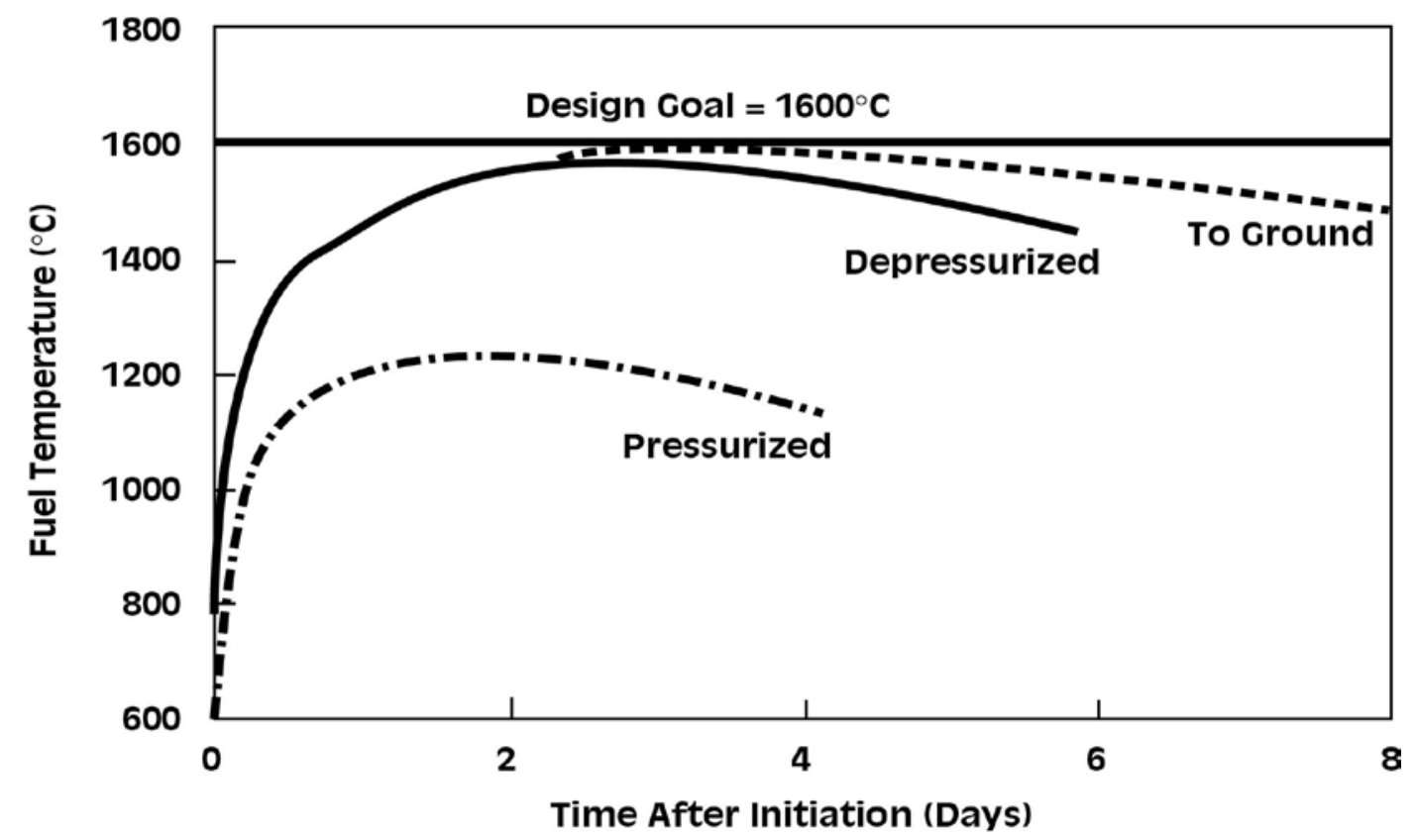

Fig. 9. Predicted peak fuel temperatures vs time for P-LOFC, D-LOFC, and for D-LOFC accidents in which the RCCS fails (i.e., the "to ground" case, in which vessel heat is rejected to the below-ground silo).

\subsection{AIR INGRESS ACCIDENTS}

\subsubsection{Introduction}

Postulated air ingress accidents, although of very low probability in modular HTGRs, are of considerable interest to the plant designer, operator, and regulator because of the possibility that the core could sustain significant damage under some circumstances. Due to a wide range of scenarios for potential accidents, sensitivity analyses are needed to cover a spectrum of conditions affecting outcomes of the postulated accident sequences. The major factors affecting potential core damage are the size and location of primary system leaks, flow path resistances, the core temperature distribution, and the long-term availability of oxygen in the incoming gas from a reactor building. Typically, all the incoming oxygen entering the core area is consumed within the reactor vessel, so it is more a matter of where, not whether, oxidation occurs in the reactor primary system. 
Sensitivity studies can help quantify the uncertainties in predictions of accident outcomes and can lead to an improved understanding of important elements of the accident phenomena. They also indicate where more or less emphasis should be put on elements of plant design, R\&D, and improved component and subsystem performance and reliability.

In the scenarios addressed here as reference prismatic (core) modular reactor cases, a long-term LOFC is assumed along with a primary system D-LOFC accident from full power. This is followed by a SCRAM and eventually by an ingress of air that replaces the remaining helium in the reactor vessel, with a subsequent circulation of the air by natural convection. Early in the D-LOFC accident transient (typically before ingress begins), the two major factors affecting the predicted maximum fuel temperatures are the assumed: decay heat vs time and the core effective thermal conductivity.

For ATWS cases, the results would be essentially the same, as long as a SCRAM or other sufficient insertion of negative reactivity occurred within $~ 2$ days (before a recriticality, due mainly to decay of xenon poisoning). Other scenarios involving D-LOFC initiation from lower power levels or with lower temperatures would normally be expected to result in lesser consequences. However, as is noted in the studies, this is not necessarily the case, at least in terms of potential fuel and core structural damage from oxidation. Forced circulation following depressurization might lead to more serious consequences if the circulating gas contained a significant fraction of oxygen. Such scenarios are not addressed here.

Air ingress accident sequences that could result in significant core damage are usually classified as very unlikely. These scenarios are also very slow to develop and would leave much time and many opportunities for operator actions to mitigate (or exacerbate) damage.

It is generally recognized that predictions of core oxidation consequences become less accurate as postulated damages increase. For oxidation of a pebble bed reactor core, for example, the oxidation is likely to be especially nonuniform, making it difficult to predict how much of the fuel particles in the centers of the pebbles would be exposed. Asymmetric damage would also degrade the accuracy of predicted core gas flow and flow distributions due to bed geometry changes. In prismatic cores, significant oxidation within the graphite coolant channels could have a potentially undesirable effect of lowering core flow resistance.

The air ingress accident sensitivity simulations discussed here have utilized the ORNL Graphite Reactor Severe Accident Code (GRSAC) [Ref. 19], which calculates accident responses using graphite oxidation models described in detail in Ref. 20. Sensitivity studies for a wide range of air ingress accidents are described in Ref. 21. The reactor models referenced in this discussion are intended to represent "typical" prismatic core design parameters and are not necessarily specific to particular designs.

\subsubsection{Key Elements of Air Ingress Accident Scenarios}

Key factors in air ingress accident scenarios are the net airflow rate into the reactor vessel and core and ultimately the availability of fresh air (oxygen) over the course of the accident. The net airflow through the core is strongly dependent on the buoyancy forces due to differential temperatures as well as flow resistances in the core and other primary flow paths and at the break(s). Early GRSAC predictions [Ref. 22] of core graphite oxidation used pessimistic assumptions about the availability of "fresh air" potentially ingested into the vessel and core (i.e., it was unlimited). More realistic cases account for the RPV being in a cavity or confinement building (vault), where fresh air in-leakage is limited and gaseous products from the accident collect and become components of the inlet gas for subsequent core ingress.

For a single break or opening in the primary system, calculations and experiments have shown that there may be long delays before a sustained, significant net air inflow into the core is established. The 
responsible phenomenon is a helium bubble in the top area of the vessel that persists and inhibits recirculation flows within the core. This process involves air diffusion into the helium bubble. Experiments and analyses by JAERI [Ref. 23] and others have shown that this bubble could be effectively maintained in the vessel for days. For idealized experimental conditions, these predictions have proven quite accurate. However, for more realistic break situations, actual conditions would be complex and could result in large uncertainties in the time for the significant ingress flow to start. Additional uncertainties would come from potential operator actions that are likely to occur during the days following a major event such as a D-LOFC. Because of these uncertainties, ingress flow start times in these analyses are inputs that are treated parametrically.

For an even more unlikely case of a double break allowing outside access to both the top and bottom of the core, this chimney-like configuration would promote a higher net air ingress flow with minimal delay. However improbable, NRC requested consideration of this event during its reviews of the MHTGR [Ref. 18].

Once a net air ingress flow is established, oxidation would typically begin in the lower part of the core, or in the bottom support and reflector areas. However, for the low flow rates expected, oxygen is likely to be depleted before reaching the active core area. In some higher ingress flow rate scenarios, however, oxidation would occur in the lower part of the active core, as it would also in cases where the bottom reflector has cooled sufficiently such that no significant oxidation occurs there.

Variation in the time delay for a net air ingress flow typically has little effect on peak fuel temperatures, which occur higher up the core. Even with no mitigation, the oxidation rate should eventually decrease due to limitations in available oxygen. For long-term air ingress accidents, it is important that the ultimate availability of fresh air is limited and considered in the analysis. Models used in GRSAC for predicting graphite oxidation in the core and reflector regions [Ref. 20] are derived from extensive experimental data, but large uncertainties in these predictions are expected because of the complexity of both the oxidation process and the experimental measurement techniques, in addition to wide variations in graphite properties. The heterogeneous oxidation model used involves estimating the oxidation rate two ways at each location (node) and each time step: first, assuming chemical control of the oxidation rate and second, assuming oxygen mass transport limitations. The lower of the two estimates is selected as controlling the overall rate. The oxidation rate under the chemical control (Arrhenius) of a large graphite block is assumed to occur within an active reaction zone, the thickness of which depends on temperature. The reaction rate within this zone may be predicted using published correlations. A first-order variation with oxygen pressure is typically assumed, along with allowance for rate variation with burnoff. Standard correlations can be assumed for oxidation under mass transfer control, which applies to the higher temperatures.

Prediction of damage to hot core and support structures that encounter the oxygen is very much dependent on whether the oxidation takes place in the chemical-control or the mass-transfer-control regime.

Chemical-control (lower-temperature) oxidation is slower, but its penetration into graphite structures does considerably more damage (per percent oxidation) than does the mass-transfer-limited process, which occurs primarily at the surface [Ref. 24]. Hence analyses estimating structural damage require detailed modeling that takes these factors into account.

In the GRSAC model it is assumed that $\mathrm{CO}_{2}$ is the principal oxidation product and that all the oxidative heat is deposited in the graphite. Carbon monoxide production is currently ignored. Carbon monoxide can be formed in high-temperature reactions of the $\mathrm{CO}_{2}$ with graphite (the Boudouard reaction: $\mathrm{CO}_{2}+\mathrm{C}=$ 2CO). Although it is an endothermic reaction, ignoring it is "conservative" when predicting peak temperatures, but its omission could lead to underpredictions of the amount of graphite lost and thus could result in a low estimate of the potential for fuel damage in the hotter part of the core. Estimates of 
the total impact (on weight loss) of CO reactions in ingress accidents are typically on the order of 20\% or less, or well within the uncertainty range when modeling only the $\mathrm{CO}_{2}$ reaction.

Tests of irradiated TRISO fuel subject to oxidation have shown that fission products were not released if the particle temperatures were less than $\sim 1200^{\circ} \mathrm{C}$ [Ref.13]; that is, the SiC protective coatings remained intact. Hence fuel damage in the lower core regions, where (in typical scenarios) maximum fuel temperatures do not exceed $1200^{\circ} \mathrm{C}$, fuel particle oxidation (with fission product release) does not appear to be a critical concern.

\subsubsection{Air Ingress Accident Conclusions}

- The sooner the start of an ingress flow, the less cooldown time is left for the lower support structure, and thus the more the oxidation would occur in the bottom part of the support structure. Conversely, if the ingress flow starts later, more time is available for cooldown of the bottom structure, and oxidation would be more likely to occur in the fuel regions. By inference from these results, D-LOFC air ingress accidents initiated from lower-power and/or lower-temperature operating conditions could result in greater fuel oxidation but less bottom structure oxidation.

- A reduction of air-inlet leakage into the vault could result in significantly less long-term oxidation. The long-term overall oxidation rate would be proportional to the oxygen in-leakage until such time as the core cools sufficiently.

- A more rapid cooldown of the vault gas and a higher helium leakage rate would result in a more rapid increase in cold-leg density, and thus a higher ingress flow rate, but with only a modest increase in overall oxidation rate. More oxidation could occur in the fueled section of the core.

- Although a leak-tight containment case would show better results for potential damage from graphite oxidation, it would clearly not be recommended from an overall safety standpoint. In DLOFC accidents, a leak-tight containment would pressurize, and unlike the case for LWRs, where steam would be released, its discharge would not condense and thus would not lower the pressure. In a subsequent heatup accident progression, any fuel failure and fission product release into the containment that might occur in an eventual failure of a pressurized containment would have a significant driving force to disperse contamination into the environment. On the other hand, with a vented reactor building, there would be no substantial driving force available, and any further leakages could be much more readily filtered.

- The temperature of fuel subject to oxidation attack is likely to be below the limits for SiC TRISO coating failure.

- Most core support graphite oxidation is likely to be in the chemical-control (lower-temperature) regime, which would mean it would oxidize more slowly but would cause proportionately more structural damage than for oxidation occurring in the mass-transfer-limited (higher-temperature) regime.

- In a D-LOFC, the core would stay hot enough to oxidize for a long time, so any reactor building air in-leakage would be a potential oxygen source. 


\subsection{WATER/STEAM INGRESS ACCIDENTS}

\subsubsection{Introduction}

The level of concern for water/steam ingress accidents in a modular HTGR depends significantly on the primary system design. For designs in which an intermediate heat exchanger couples the core to the balance of plant, or if it is a direct-cycle gas turbine (Brayton cycle) design, the probability of significant water/steam ingress would be minimal. The lower-pressure water sources in indirect cycle, Brayton cycle, and steam cycle designs may include water in the secondary side of the heat exchanger of the shutdown cooling system, in the helium circulator cooling system, or in precoolers and intercoolers. Event sequences involving tube failures in such coolers are unlikely to result in water ingress because water pressures are typically kept below helium pressures; however, some unlikely operational sequences have been identified that could lead to some water ingress.

Because of the potential for breaks in tubing or other boundary structures, ingress probabilities are much higher for designs with in-line steam generators (SGs), where the pressure of the secondary water/steam is usually much higher than that of the primary helium. In these cases, design provisions such as isolation of the water source and evacuation of the high-pressure water inventory are usually made to limit the effect and amount of water ingress.

\subsubsection{Consequences and Safety Aspects}

Water/steam ingress into a hot gas-cooled reactor core causes three major safety concerns, namely a positive reactivity insertion, chemical attack on the graphite, and a potential breach in the primary system due to opening of the safety relief valves.

Modular HTGR cores are usually undermoderated by design, so a moisture ingress event can cause a positive reactivity insertion. An undesirable side effect is the reduction of control rod worth due to shielding effects. The extent of the reactivity insertion depends on the degree of undermoderation and the total mass of moisture penetrating the core. If uncorrected, these positive reactivity insertions could cause significant transient increases in reactor power and core temperatures.

Chemical attack by moisture causes oxidation and corrosion of the graphite material in the core and, if exposed, to the coated fuel particles as well. In cases of very large, long-term ingress events, it could also challenge the structural integrity of graphite reactor internals and fuel elements. The reaction of moisture with graphite causes an increase in primary pressure and produces gases, including carbon monoxide and hydrogen, which present additional safety concerns. Unlike most chemical reactions between graphite and air, graphite-water reactions at high temperatures are endothermic.

For steam cycle designs, SG tube ruptures can cause pressure increases and surges in the primary system. In some postulated low-probability sequences, the primary pressure could eventually increase enough to actuate safety relief valves. The releases of primary system gases to the atmosphere could be cyclic or, in the case of stuck-open valve(s), continuous.

Moisture in the primary can also lead to the washoff of radioactivity plated out on tube and graphite surfaces and, if released, could add to the source terms.

Because significant moisture ingress is very unlikely except in the case of HTGRs with in-line SGs, the following discussions consider only those designs. More detailed discussions of steam/water ingress consequences and safety aspects are found in Refs. 17 and 25. 


\subsubsection{Modeling and Data Needs for Water Ingress Accidents}

Water ingress events typically involve complex interactions of neutronics, thermohydraulics, chemical reactions, and radioactivity releases. Within the accident probability ranges of interest, detailed computer codes and models need to calculate the rate and amount of water/steam ingress, the reactivity effects and resulting power transients, pressure and temperature transients, production of oxidization gases, and the source terms. Due to the wide boundaries of potential scenarios, sensitivity analyses considering varieties of operational responses and model-parameter uncertainty bounds are desirable.

If one assumes, in the range of accident scenarios, that the only means for FP escape to the environs is via operation of the primary system pressure-relief valves, then a crucial parameter in the accident sequences is primary system pressure. Coincident rapid depressurizations (e.g., due to breaks in the primary system) are considered to be independent of water ingress accidents because that coincidence would involve the simultaneous occurrence of two very-low-probability events.

Primary system pressure is affected by the amount of steam (or water) ingress, reaction gas generation, system temperatures (e.g., core heatup), and the timing of the sequence elements. For cases where relief valves open on high pressure, cycling of the valves would impact the amount of gas release (and dose) involved, as would the possibility of valve(s) sticking open.

For design basis scenarios, it is typically assumed that primary system moisture monitors operate and successfully activate SG isolation valves, thus cutting off the water ingress source. This would likely result in a modest amount of total water ingress, with very little effect on reactivity, core temperature changes, water gas generation, or graphite oxidation. With no other breaches, there would be no FP releases to the environment. On the other hand, scenarios with the failure of moisture monitor trip and operator actions could ultimately need to rely on a high primary system pressure trip (and potentially subsequent safety valve actuation), which would also activate the SG isolation valves. In this case, relief valve actuation would maintain the system pressure within design limits but at the cost of potentially releasing FPs to the environment. Repeated openings of the relief valve(s) would continue to maintain a "safe" pressure but would continue to release FPs.

In the case of a controlled response of the reactor to a trip (or SCRAM), two assumptions can be made regarding the cooldown of the core. One is that upon SCRAM, the main cooling system functions to quickly cool the core down to temperatures at which the reactions of the steam/water with the graphite would be markedly reduced, thus quickly limiting the chemical effects of the ingress. The other assumption is that the reactor control system would attempt to balance the power reduction (from a SCRAM) with a simultaneous cooling flow reduction so as to avoid a rapid cooldown that could cause transient thermal stresses in the block fuel, reflectors, and support structures. In the latter case, potential thermal stress problems would be avoided, but, at the sustained higher temperatures, the core would be more prone to a prolonged chemical attack.

Events involving moisture ingress during shutdown and refueling modes of operation could increase reactivity more than events during normal operation. For ingresses in the liquid form, much more moderation would be occurring than with high-temperature steam, where the density would be much lower. Moisture monitors may not also be able to detect the ingress and conditions associated with the presence of moisture in liquid form (e.g., saturation levels do not indicate the status of water concentrations).

In the events and situations noted, there are cases where changes in operating conditions (or model assumptions) could have significant effects on predictions of total water ingress and total FP releases. For 
long-term accident sequences, possibilities for operator actions also need to be factored in (where prescribed or "intuitive" interventions may or may not be beneficial).

Because of these uncertainties in scenario outcomes (and other factors), it is imperative to acquire or develop a systems accident code capable of simulating phenomena associated with moisture ingress and to use it to do sensitivity studies to acquire a good understanding of the potential consequences of moisture ingress events as well as to optimize the design of mitigation systems in the process. Also, in certain cases, such as those where one phenomenon is important in one accident sequence but unimportant in another, multiple evaluations would be needed.

Integrated accident code features should include the following:

- reactivity effects of steam/water ingress (increased reactivity with undermoderated core);

- reduction of control/shutdown rod worth with increased moisture density;

- moisture detection instrumentation, protection system logic, and equipment actuation (such as isolation valves);

- $\quad$ core and primary coolant temperatures and flow distributions vs time;

- SCRAM action;

- all factors affecting pressure increase in the primary system;

- $\quad$ RPV pressure relief system activation and response;

- $\quad$ plant protection system (safety and nonsafety) response;

- confinement/containment release characteristics;

- operating or startup or shutdown conditions;

- SG isolation and dump system operation;

- graphite oxidation/corrosion products for the graphites qualified for in-vessel use;

- FP releases from fuel and graphite; and

- explosive gas mixtures - in both the RPV and the reactor building.

\subsubsection{Water Ingress Safety Analysis}

Analyses are performed for HTGR water ingress events to determine the specific system response to the scenarios and to assess the consequences in terms of dose, impact on plant components, and identification of recovery sequences.

The analysis of a water ingress event in a conventional steam-cycle HTGR, such as the MHTGR, would typically include the following steps:

- identify leak size,

- determine ingress rate,

- evaluate water/steam transport,

- determine protection system response, and

- evaluate consequences (oxidation, FP transport).

An integrated transient model is needed to calculate the overall system response based on the calculated water ingress rate. Key results are the reactivity transient and resulting power, system-pressure, and temperature responses. 
Because HTGR designs are undermoderated, any additional neutron moderation (from the moisture) will increase the reactivity, mainly from the combined effects of three phenomena:

- fewer thermal neutrons are available for ${ }^{235} \mathrm{U}$ fission due to neutron absorption by hydrogen.

- the neutron energy spectrum softens (fewer high-energy neutrons), which increases the fission cross section and decreases resonance capture in ${ }^{238} \mathrm{U}$.

- the reduced neutron leakage out of the core region decreases ex-core control rod effectiveness and has a potential effect on reserve shutdown system worth.

Quantifying the system reactivity behavior during water ingress events depends on several factors:

- $\quad$ system size, geometry, and the moderator material;

- fuel and moderator temperatures;

- fuel type; and

- burnup. (a beginning-of-cycle core, with fresh fuel and deep control rods, behaves differently from the same core at the end of cycle, when more plutonium is present and the control rods are almost completely out of the core.)

The reduction of control rod worth for HTGR thermal systems is an important factor. The decrease in shutdown margin and the ingress events at cold shutdown core states need to be taken into account.

\subsubsection{Summary and Conclusions Relating to Water Ingress Events}

Assessments of modular HTGR moisture ingress events need to determine the impacts of postulated water/steam ingress events to better understand the needs for additional R\&D, analytical tools, and experiments to validate and upgrade available accident codes. Consideration here was given mainly to the prismatic core gas-cooled reactor configurations incorporating an SG within the primary circuit.

In MHTGR safety studies, the dynamic effects of water ingress into an operating and a shutdown core were considered of high importance. The 1986 MHTGR preliminary safety information document (PSID) [Ref. 26] included several scenarios of steam leaks and tube breaks, with and without safety system intervention, including SCRAM, turbine trip, isolation, and dump valve closures. The higher-probability scenarios resulted in modest power and peak fuel temperature increases well within material limits and with no fuel failure expected to occur. The consequences of beyond-design-basis events were more significant, with the potential for more water entering the primary system and leading to more graphite oxidation. The primary pressure relief valve cycles resulted in releases of radionuclides. However, the PSID analysis concluded that the oxidation and the total dose to the environs would be well within acceptable limits. Even so, sensitivity studies with variations in both sequence assumptions and models used are recommended. Such studies require systems-accident codes capable of simulating all those noted phenomena associated with moisture ingress and must be used to acquire a better understanding of the potential consequences of moisture ingress events and to optimize the design of mitigation systems in the process.

FP releases would result mainly from removal of FP deposits from primary system surfaces and from chemical reactions with the FPs and graphite. Moisture ingress would probably have no significant effect on intact fuel particles, only on defective particles in which the kernels are exposed. Releases to the environment would occur only upon relief valve opening(s). More data and improved modeling for decontamination factors for the reactor building would be useful.

For the long term, low levels of moisture present during normal operating conditions could be a significant concern because oxidation rates and the physics for diffusion-controlled oxidation are not well 
understood. Additional R\&D would be required to accurately calculate the oxidation rates, the effects on material performance, and the mechanisms controlling the oxidation behavior at high temperatures and in low-moisture environments. Long-term structural damage would be a consideration because it may affect initial conditions in the evaluation of significant moisture ingress accidents.

\subsection{REACTIVITY ACCIDENTS}

\subsubsection{Initiating Events}

Reactivity events are those in which positive or negative reactivity is accidentally or inadvertently introduced for various reasons. Typical initiators postulated to cause reactivity events are

- control rod or rod bank withdrawal;

- control rod ejection (typically prevented by design);

- xenon oscillation;

- inadvertent control rod action due to power measurement error or operator error;

- sudden increase or decrease of the primary heat removal rate;

- compaction of a pebble bed core caused by earthquake;

- a break of heat transfer tubes in an SG or other water-cooled heat exchanger that could result in water or steam ingress into the core (there is also a reduction of control/shutdown rod worth with increased moisture density);

- control rod drop; and

- fuel-loading errors (both for pebble-bed and prismatic cores).

Control rod ejection events may also be associated with a primary system rupture (such as a control rod housing failure). Such a rod ejection event may be eliminated from consideration by a blocking design. Some of the initiators are discussed further in other sections (such as water/steam ingress).

For LOFC + ATWS events (well beyond design basis), recriticality due to xenon poisoning decay (after $\sim 2$ days) would increase the fuel temperatures as the reactor returned to some power level that would depend on the heat loss. The argument here is that some negative reactivity insertion could certainly be implemented before a recriticality occurred. The peak fuel temperatures would be dependent on design features, operating history, and heat losses, but in many simulated cases, the peak temperature resulted in TRISO fuel damage. If the operator were to restart the shutdown coolant system while the ATWS persisted, peak fuel temperatures would increase significantly due to the "selective undercooling" phenomenon as described in Sect. 6. If forced primary circulation persisted inadvertently during certain postulated ATWS scenarios, fuel temperatures could go much higher than the limiting values.

\subsubsection{Consequences and Safety Aspects}

In an earthquake, positive reactivity might be inserted in a pebble bed core by two mechanisms. One is the reduction of the core porosity (compaction from shaking) and consequently a reduction in the neutron leakage. Another is a shift upward in the positions of the control rods relative to the top surface of the active core.

In summary, a wide variety of initiators are capable of causing reactivity disturbances. For most of them, the relatively large negative temperature-reactivity feedback coefficient typical of the modular HTGR cores tends to make these events inconsequential from a safety standpoint. Other reactivity variations, such as those due to variations in reflector temperature (center and side) changes in LOFC accidents are very slow but can have an effect on recriticality in an ATWS and on shutdown margins because reflector temperature-reactivity feedback coefficients may be positive. 


\section{CONCLUSION}

Safety analyses covering a very wide range of accident sequence probabilities have shown modular HTGR designs to be very robust due to their inherent safety design and accident mitigation features. These combine to preclude extensive core damage such as that possible with today's LWRs. 


\section{REFERENCES}

1. International Atomic Energy Agency, Considerations in the Development of Safety Requirements for Innovative Reactors: Application to Modular High-Temperature Gas-Cooled Reactors, IAEA-TECDOC1366, Vienna, Austria, August 2003.

2. US Nuclear Regulatory Commission, Enterprise Content Management, NUREG -1954, Washington, DC, September 2010.

3. International Atomic Energy Agency, Proposal for a Technology-Neutral Safety Approach for New Reactor Designs, IAEA-TECDOC-1570, Vienna, Austria, September 2007.

4. US Nuclear Regulatory Commission, Preapplication Safety Evaluation Report (PSER) on the Modular High-Temperature Gas-Cooled Reactor (MHTGR), NUREG-1338, Office of Nuclear Reactor Regulation, Washington, DC, December 1995.

5. S. Shiozawa, Safety Logics for HTGR Safety Systems, IAEA Technical Meeting on Safety Aspects of MHTGRs, Beijing, China, October 2007.

6. P. G. Robinson, PBMR Safety Analysis Software Development and V\&V, International Atomic Energy Agency Technical Meeting on Safety Aspects of MHTGRs, Beijing, China, October 2007.

7. Y. Sun and D. Xue, “Consideration on General Safety Design Criteria of HTR-PM,” International Atomic Energy Agency Technical Meeting on Safety Aspects of MHTGRs, Beijing, China, October 2007.

8. Idaho National Laboratory, Modular HTGR Safety Basis and Approach, INL/EXT-11-22708, Idaho Falls, Idaho, August 2011.

9. Idaho National Laboratory, Next Generation Nuclear Plant Probabilistic Risk Assessment White Paper, INL/EXT-11-21270, Idaho Falls, Idaho, September 2011.

10. US Nuclear Regulatory Commission, Next Generation Nuclear Plant Phenomena Identification and Ranking Tables (PIRTs), (Six Volumes), NUREG/CR-6944, Washington, DC, March 2008.

11. S. J. Ball et al., Next Generation Nuclear Plant GAP Analysis Report, ORNL/TM-2007/228, , Oak Ridge National Laboratory, Oak Ridge, Tennessee, July 2008.

12. Idaho National Laboratory, NGNP Research and Development Status, INL/EXT-10-19259, Idaho Falls, Idaho, August 2010.

13. International Atomic Energy Agency, Fuel Performance and Fission product Behavior in Gas-Cooled Reactors, IAEA-TECDOC-978, Vienna, Austria, November 1997.

14. C. A. Baldwin et al., "First Elevated-Temperature Performance Testing of Coated Particle Fuel Compacts from the AGR-1 Irradiation Experiment," Proceedings of the $6^{\text {th }}$ International Topical Meeting on High Temperature Reactor Technology HTR2012, Tokyo, Japan, October 28-November 1, 2012.

15. R. N. Morris et al., Performance of AGR-1 Fuel at Elevated Temperature: Fission Product Retention at 1600, 1700, and $1800^{\circ} \mathrm{C}$, VHTR R\&D FY13 Technical Review Meeting, Idaho Falls, Idaho, May 7-9, 2013.

16. H. Kalinowski, Core Physics and Pebble Flow-Examples from THTR Operation, Safety Aspects of HTR Technology-NRC visit in Germany, 23-26 July 2001, GRS, pp. 430-447 and 11-13, Accession No. ML092250104 at http://adams.nrc.gov/wba/. 
17. International Atomic Energy Agency, Accident Analysis for Nuclear Power Plants with Modular High-Temperature Gas-Cooled Reactors, IAEA Safety Reports Series No. 54, Vienna, Austria, April 2008.

18. ACRS Subcommittee Meeting on Advanced Reactor Designs, August 3, 1988

19. S. J. Ball, Graphite Reactor Severe Accident Code (GRSAC) for Modular High-Temperature GasCooled Reactors (HTGRs) User Manual, ORNL/TM-2010/096, Oak Ridge National Laboratory, Oak Ridge, Tennessee, 2010.

20. R. P. Wichner and S. J. Ball, Potential Damage to Gas-Cooled Graphite Reactors due to Severe Accidents, ORNL/TM-13661, Oak Ridge National Laboratory, Oak Ridge, Tennessee, 1999.

21. S. J. Ball, M. Richards, and S. Shepelev, "Sensitivity Studies of Air Ingress Accidents in Modular HTGRs,” Nuclear Engineering and Design 238, 2935-2942, 2008.

22. S. J. Ball, "Sensitivity Studies of Modular High-Temperature Gas-Cooled Reactor Postulated Accidents,” Nuclear Engineering and Design 236, 454-462, 2006.

23. M. Hishida and K. Takada, "Study on Air Ingress during an Early Stage of a Primary-Pipe Rupture Accident of a HTGR,” Nuclear Engineering and Design 126, 175-187, 1999.

24. C. I. Contescu et al., "The Effect of Microstructure on Air Oxidation Resistance of Nuclear Graphite,” Carbon 50, 3354-3366, 2012.

25. S. J. Ball, G. Strydom et al., Assessment of NGNP Moisture Ingress Events, INL/EXT-11-21397, Idaho National Laboratory, Idaho Falls, Idaho, 2011.

26. US Department of Energy, Preliminary Safety Information Document (PSID) for the Standard MHTGR, DOE-HTGR-86-024, Washington, DC, 1992. 